\title{
Attribution of the seasonality of atmospheric heating changes over the western tropical Pacific with a focus on the spring season
}

\author{
Shuheng Lin ${ }^{1}$. Song Yang ${ }^{1,2,5} \cdot$. Shan $\mathrm{He}^{2,3} \cdot$ Zhenning $\mathrm{Li}^{4} \cdot$ Jiaxin Chen ${ }^{1} \cdot$ Wenjie Dong ${ }^{1,2} \cdot$ Jiaxue $\mathrm{Wu}^{3}$
}

Received: 5 June 2021 / Accepted: 20 October 2021 / Published online: 3 November 2021

(c) The Author(s) 2021

\begin{abstract}
Atmospheric diabatic heating, a major driving force of atmospheric circulation over the tropics, is strongly confined to the tropical western North Pacific (TWNP) region, with the global warmest sea surface temperature (SST). The changes in diabatic heating over the TWNP, which exert great impacts on the global climate system, have recently exhibited a noticeable seasonal dependence with a remarkable increase in boreal spring. In this study, we applied observations, reanalysis data, and numerical experiments to investigate the causes of the seasonality in heating changes. Results show that in boreal spring convection is more sensitive to the TWNP SST, leading to a more significant enhancement of deep convection, although the increase in the SST is nearly the same as that in the other seasons. In the non-spring seasons, the enhanced convection due to increased local SST is suppressed by the anomalous anticyclonic wind shear over the TWNP, generated by the easterly wind anomalies induced by the tropical Indian Ocean (TIO) warming via the Kevin waves. However, the TIO warming does not show any suppressing effect in spring because it is much weaker than that in the other seasons and thus the warming itself cannot induce sufficient convective heating anomalies to excite the Kelvin waves.
\end{abstract}

Keywords Atmospheric heating $\cdot$ Tropical western North Pacific $\cdot$ Deep convection · Sea surface temperature

\section{Introduction}

In the tropics, atmospheric diabatic heating, especially the latent heating from cumulus convective condensation, is the major driving force of large-scale atmospheric circulation (Webster 1972). The tropical western North Pacific (TWNP; $\left.125^{\circ}-160^{\circ} \mathrm{E} / 0^{\circ}-20^{\circ} \mathrm{N}\right)$ is one of the largest heating sources

Song Yang

yangsong3@mail.sysu.edu.cn

1 School of Atmospheric Sciences, Sun Yat-sen University; and Southern Marine Science and Engineering Guangdong Laboratory (Zhuhai), Zhuhai, China

2 Guangdong Province Key Laboratory for Climate Change and Natural Disaster Studies, Sun Yat-sen University, Zhuhai, China

3 School of Marine Sciences, Sun Yat-sen University; and Southern Marine Science and Engineering Guangdong Laboratory (Zhuhai), Zhuhai, China

4 Division of Environment and Sustainability, Hong Kong University of Science and Technology, Hong Kong, China

5 School of Atmospheric Sciences, Sun Yat-sen University, Zhuhai 519000, China in the tropics (Webster and Lukas 1992), where sea surface temperature (SST) can exceed $28{ }^{\circ} \mathrm{C}$. A huge amount of latent heating is found in this region due to strong convective activities and heavy precipitation (Huang and Sun 1992). The temporal and spatial variations of the heating over the TWNP exert significant impacts on regional and global climate (Simmons 1982; Nitta 1987; Yang and Webster 1990; Huang and Sun 1992; Rodwell and Hoskins 2001).

The long-term changes in TWNP diabatic heating and the resultant impacts on regional climate have received considerable attentions in recent studies. Park and An (2014) argued that the long-term changes in convection heating over the TWNP could make great contributions to the changes in Pacific atmospheric circulation by modifying the meridional position of the western North Pacific jet stream. He et al. (2016) revealed that in the boreal summer of the past half a century, diabatic heating in the mid-troposphere increased over the South China Sea (SCS) and TWNP, consistent with the enhanced convection and increased precipitation in the region. They further demonstrated that the increased heating strengthened the upper-tropospheric South Asian high and formed a lower-tropospheric cyclonic circulation over the SCS and the TWNP, consequently intensifying a dry 
climate in continental South Asia and a moist climate in the SCS and the TWNP. Li et al. (2016b) found that the springtime heating over the SCS and the TWNP also significantly increased during the satellite era. The enhanced heating leads to suppressed springtime rainfall over southern China via heating-induced anomalous overturning circulation. As such, an investigation of the long-term changes in atmospheric heating over the TWNP in all seasons is needed for understanding the Pacific and East Asian climate changes.

While the above-mentioned studies showed great progress in understanding the impact of heating changes on the climate, the causes for the heating changes were not elaborated. Note that direct observational measurements of diabatic heating profiles are difficult (Ling and Zhang 2013). Diabatic heating is often estimated by the apparent heat source (Q1) derived from global data assimilation products, commonly known as global reanalyses, using the method given in Yanai et al. (1973) (also see He et al. (2016) and Li et al. (2016b)). However, the global observing system used for data assimilation underwent large changes in 1979. The changing observing system may have induced some spurious signals of the tropical climate changes derived from the atmospheric reanalysis products (Basist and Chelliah 1997; Bengtsson et al. 2004; Kinter et al. 2004), and thus affected the assessment of long-term trend of diabatic heating using such reanalysis data before 1979. Less effort has been devoted to studying how the TWNP heating in all seasons has changed after 1979, a period when more reliable observation and reanalysis datasets are available. In this study, we first examined the characteristics of changes in TWNP heating of all seasons during the recent decades (1979-2015) using multiple reanalysis and observations datasets. The changes in TWNP heating show a noticeably seasonal dependence: A remarkable increase is observed in the boreal spring, but not in the other seasons (Fig. 1). Therefore, we seek answers for a specific question: why does the diabatic heating increase most obviously in spring but show weak changes in the other seasons during the recent decades? Since the changes in convective heating dominate those in diabatic heating over the TWNP (Fig. 1), the mechanisms for the changes in diabatic heating are thus investigated from the perspective of the changes in deep convection in this study.

As a boundary condition of the tropical atmosphere, SST can influence deep convection through local air-sea interaction. As argued by Zhang (1993), warmer SST can supply more latent and sensible heat fluxes to the lowlevel atmosphere above, making the atmosphere have more moist static energy and thus become more unstable. Moreover, in the areas of warmer SST, the low-level convergence induced by SST gradient (Lindzen and Nigam 1987) can boost large-scale lifting, a requirement for deep convection to penetrate through the inversion above the boundary layer (Firestone and Albrecht 1986). Thus, warmer SST makes conditions favourable for deep convection. It is expected that the intensity of deep convection increases with increasing SST. However, the observed convection-SST relationship on monthly timescale shows a more complex picture (Graham and Barnett 1987; Waliser and Graham 1993; Zhang 1993; Bhat et al. 1996; Lau et al. 1997; Sabin et al. 2013). Previous studies found that when SST was below the so-called SST threshold near $27-28^{\circ} \mathrm{C}$, deep convection was weak and could rarely been observed, meaning that it was insensitive to SST changes (Gadgil et al. 1984; Johnson and Xie 2010). Around the SST threshold, the frequency and intensity of deep convection increase dramatically. Even a small change in SST can greatly alter convection, indicating a high sensitivity of convection to SST (convection-SST sensitivity; Gadgil et al. 1984; Graham and Barnett 1987). For higher SST, the convection-SST sensitivity weakens again (e.g., Waliser and Graham 1993). In this case, several studies argued that presence or absence of deep convection is more closely associated with large-scale convergence (Gadgil et al. 1984; Graham and Barnett 1987; Waliser and Graham 1993). It is thus argued that the nonmonotonic convection-SST relationship is a result of a threeway interplay among SST, convection, and convergence (Waliser and Graham 1993; Zhang 1993; Lau et al. 1997).

In addition to the influence of local SST as mentioned above, TWNP deep convection may also be affected by remote SST. The great impact of tropical Indian Ocean (TIO) SST warming on TWNP convection at the interannual-multidecadal time scales has been elaborated by many studies (Li et al. 2008; Wu et al. 2009; Xie et al. 2009; Ueda et al. 2015). The strong connection between TIO warming and TWNP convection is mainly based on the Kelvin-waveinduced Ekman divergence mechanism: the basin warming enhances convective heating over the TIO, which can induce anomalous low-level easterly wind along the equator over the Indo-Pacific region as a Kelvin wave response. In the TWNP, the magnitude of anomalous easterly wind peaks at the equator and decreases with latitude, causing anticyclonic wind shear in the low troposphere and resultant boundary-layer Ekman divergence. Then, the anomalous boundary-layer divergence leads to suppressed convection and a low-level anomalous anticyclone over the TWNP (Wu et al. 2009; Xie et al. 2009; Li et al. 2017).

A significant SST warming trend is observed in the western tropical Pacific during recent decades (Cravatte et al. 2009; England et al. 2014). This feature occurs together with a rapid surface warming in the TIO (Luo et al. 2012; $\mathrm{Li}$ et al. 2016a). Given the close relationship between SST and convection, we thus examine the impacts of TWNP and TIO SST warming on the TWNP convection in all seasons to interpret the seasonality of changes in diabatic heating. An atmospheric general circulation model (AGCM) is also 
used to identify the influence of TIO warming on TWNP convection.

The remainder of this paper is structured as follows. In Sect. 2, we introduce datasets and numerical experiments. In Sect. 3, we diagnose the changes in TWNP heating based on observations and reanalysis datasets. In Sect. 4, we investigate the influence of local SST warming on TWNP deep convection changes. The impact of TIO warming on TWNP convection is discussed in Sect. 5. Finally, summary and a further discussion are given in Sect. 6.

\section{Data and numerical experiments}

\subsection{Data}

To quantify the changes in diabatic heating over the TNWP during the recent decades, daily atmospheric data from the European Centre for Medium-range Weather Forecast (ECMWF) interim reanalysis (Dee et al. 2011), namely, the ERA-Interim Reanalysis, are used to calculate atmospheric apparent heating Q1. The monthly atmospheric data used in this study are also from the ERA-Interim. The ERA-Interim Reanalysis dataset is on a $1^{\circ} \times 1^{\circ}$ grid, and covers the period from 1979 to the present. Monthly deep convection heating and atmospheric diabatic heating are from the National Centers for Environmental Prediction (NCEP) Climate Forecast System Reanalysis (CFSR), with a $1^{\circ} \times 1^{\circ}$ resolution and a time span from 1979 to 2010 (Saha et al. 2010). The precipitation data used are the monthly Global Precipitation Climatology Project (GPCP), version 2.2, available since 1979 with a spatial resolution of $2.5^{\circ} \times 2.5^{\circ}$ (Adler et al. 2003). The Climate Prediction Center Merged Analysis of Precipitation (CMAP; Xie and Arkin 1997) is used for validations. The NOAA Interpolated Outgoing Longwave Radiation (OLR), available from 1974 to the present (Liebmann 1996), is used as a proxy for atmospheric deep convection. The
SST data are the Hadley Centre Sea Ice and Sea Surface Temperature (HadISST), version 1 (Rayner et al. 2003), on a $1^{\circ} \times 1^{\circ}$ grid from 1870 to the present. The NOAA Extended Reconstructed SST V4 (ERSST4; Huang et al. 2015) and Centennial in situ Observation-Based Estimates (COBE) SST data (Folland and Parker 1995) are also used for validations.

\subsection{Numerical experiments}

The National Center for Atmospheric Research (NCAR) Community Atmosphere Model version 5 (CAM5), which is the atmospheric component of the Community Earth System Model (CESM1.1.2; Hurrell et al. 2013), is used to investigate the impact of observed TIO warming on TWNP deep convection. The "F_2000 component set" is implemented in the CAM5 experiments with a resolution of $1.9^{\circ} \times 2.5^{\circ}$ (longitude $\times$ latitude) and 26 vertical levels. The solar forcing, greenhouse gases, ozone concentration, and aerosols are all fixed at the levels of year 2000 .

The CAM5 experiment design is summarized in Table 1 . The boundary condition of SST in the control run (CTRL) is prescribed using the monthly climatological SST field during the period of 1981-2000. In addition, four sensitivity experiments, TIO_MAM, TIO_JJA, TIO_SON, and TIO_DJF (see Table 1), are conducted with different boundary conditions of SST in the TIO portion of $40^{\circ}-110^{\circ} \mathrm{E} / 30^{\circ} \mathrm{S}-30^{\circ} \mathrm{N}$. For instance, in the TIO_MAM run, the SST warming anomalies observed in March, April, and May in the TIO (with respect to the SST trend in 1979-2015 derived from the HadISST) are superimposed on the corresponding monthly climatological SST used in the CTRL run.

The total integration length of the experiments is 40 years, and the outputs from the last 35 years are analyzed. The first five years are discarded given that it takes some time for the model to reach an equilibrium state.

Table 1 AGCM experimental design

\begin{tabular}{ll}
\hline Exp & Description \\
\hline CTRL & $\begin{array}{c}\text { AGCM run, monthly climatology SST from 1981-2000 is used as a boundary condition, and other external forcing fields are } \\
\text { prescribed using their year 2000 values }\end{array}$ \\
TIO_MAM & $\begin{array}{c}\text { Same as CTRL, but observed March-May (MAM) SST warming anomalies during 1979-2015 in the tropical Indian Ocean (TIO; } \\
40^{\circ}-110^{\circ} \text { E } / 30^{\circ} \text { S-30 }\end{array}$ \\
TIO_JJA & $\begin{array}{c}\text { Same as } \text { TIO_MAMerimposed on the corresponding monthly climatological SST used in CTRL } \\
\text { climatological SST used in CTRL }\end{array}$ \\
TIO_SON & $\begin{array}{c}\text { Same as TIO_MAM, but observed September-November (SON) SST warming anomalies are superimposed on the corresponding } \\
\text { monthly climatological SST used in CTRL }\end{array}$ \\
TIO_DJF & $\begin{array}{c}\text { Same as TIO_MAM, but observed December-February (DJF) SST warming anomalies are superimposed on the corresponding } \\
\text { monthly climatological SST used in CTRL }\end{array}$ \\
\hline
\end{tabular}




\section{Significant increase in springtime atmospheric heating}

In this section, we examine the characteristics of the changes in TWNP diabatic heating during the recent decades. Diabatic heating is often estimated as a residual of the heat budget, that is, the apparent heating Q1 as defined in Yanai et al. (1973). We calculate the changes in Q1 using the ERA-interim daily data to quantify the changes in diabatic heating. As shown in Fig. 1, the black solid and dashed lines depict the climatology and this climatology plus 37-year linear change in Q1 profile averaged over the TWNP, respectively. A remarkable increase in springtime Q1 can be seen in the free troposphere from $800 \mathrm{hPa}$ to $200 \mathrm{hPa}$, with a maximum of about $0.9 \mathrm{~K} \mathrm{day}^{-1} 37 \mathrm{year}^{-1}$ near $450 \mathrm{hPa}$ (Fig. 1a). In contrast, there are only weak changes in Q1 in the whole troposphere for the boreal autumn and winter (Fig. 1c, d). Although Q1 shows a considerable increase at $400 \mathrm{hPa}$ during boreal summer, there is no significant change in the lower troposphere (Fig. 1b). Diabatic heating is composed of radiative fluxes, latent heating due to the phase change in water, and turbulence flux of sensible heat (Yanai et al. 1973). The CFSR includes direct output heating terms related to diabatic processes. We also compare the changes in Q1 with those in the total diabatic heating estimated by the direct calculation of all direct output heating terms in the CFSR. Since the CFSR dataset just covers the period of 1979-2010, we calculate the 32-year linear change in diabatic heating of the CRSR. The red solid and dashed lines denote the climatology and the climatology plus the linear change in diabatic heating of CFSR, respectively (Fig. 1). The springtime diabatic heating in CFSR has also increased significantly in the free troposphere, which underlines the robustness of the increase in diabatic heating indicated by Q1 (Fig. 1a). Note that the changes in diabatic heating of CFSR also exhibit a prominent seasonality, showing much larger increase in spring compared with the other seasons. To identify what kind of heating dominates the changes
Fig. 1 Climatology and climatology plus linear change (units: $\mathrm{k} \mathrm{day}^{-1}$ ) of heating profile averaged over the tropical western North Pacific (TWNP; $125^{\circ}-160^{\circ} \mathrm{E}, 0^{\circ}-20^{\circ} \mathrm{N}$ ) for seasonal means of a March-May (MAM), b June-August (JJA), c September-November (SON), and $\mathbf{d}$ December-February (DJF). Black lines are for the Q1 derived from the ERAInterim. Red and blue lines are for diabatic heating (DIABH) and deep-convection latent heating (DPLH) from the CFSR. Linear changes are calculated during 1979-2015 for ERAInterim and during 1979-2010 for CFSR, respectively (a) MAM DPLH DIABH Q1 Profile

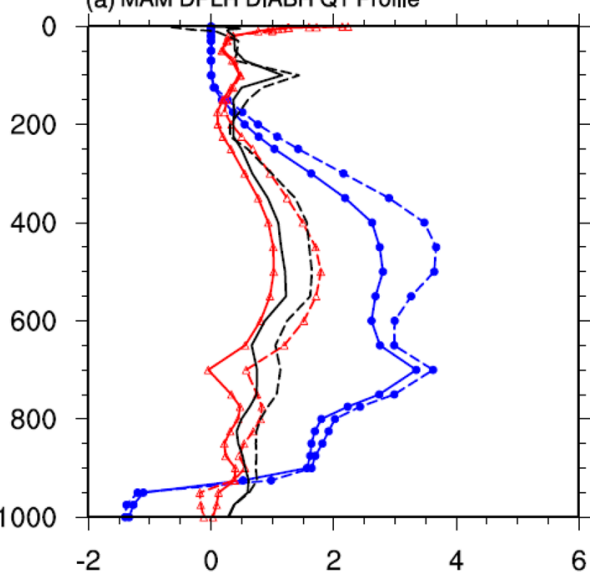

(c) SON DPLH DIABH Q1 Profile

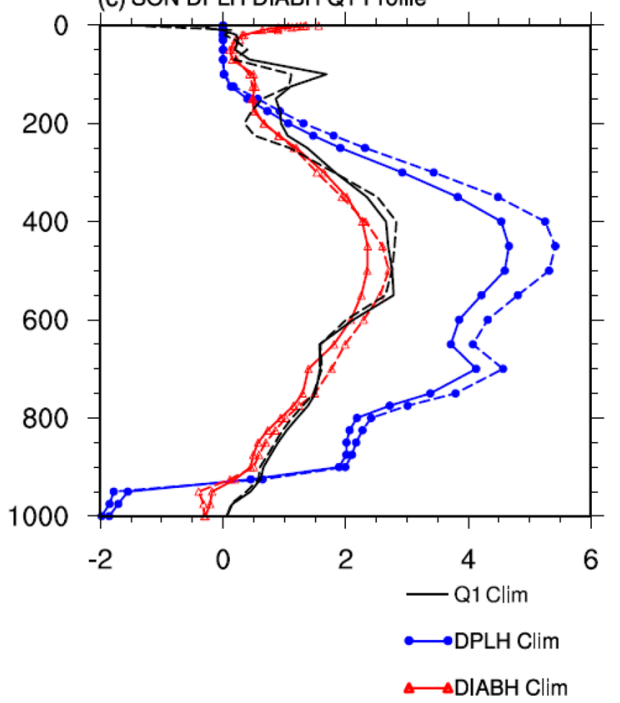

(b) JJA DPLH DIABH Q1 Profile

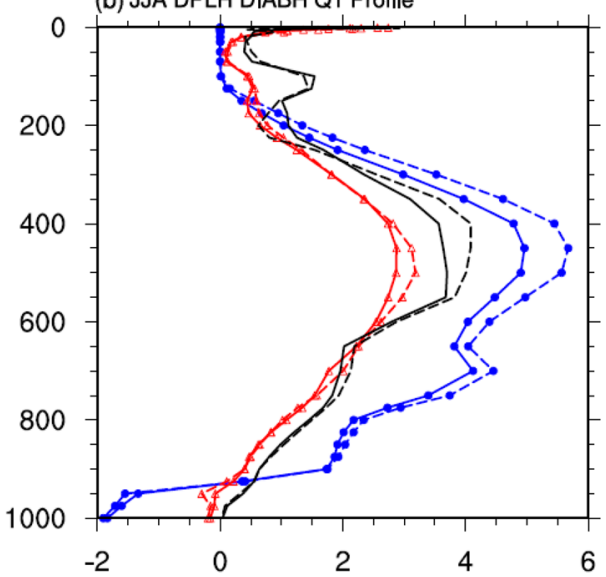

(d) DJF DPLH DIABH Q1 Profile

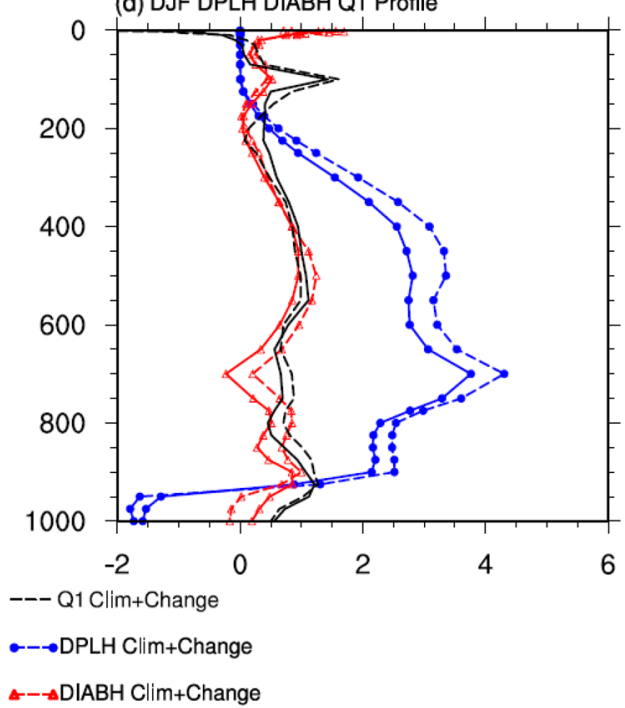


in total diabatic heating, we also calculate the changes in latent heating, radiation heating, and sensible heating in the CFSR. The deep-convection latent heating profiles from the CFSR, represented by blue solid and dashed lines, are shown in Fig. 1. The most notable change in latent heating also appears in boreal spring from $750 \mathrm{hPa}$ to $200 \mathrm{hPa}$ (Fig. 1a). Furthermore, the increment of latent heating is very close to that of diabatic heating. Quantitatively, the increase in deep-convection heating contributes to $88 \%$ of the total diabatic heating change. By contrast, the radiative heating and the sensible heating only explain $7.5 \%$ and $-2.2 \%$ of the total heating increase, respectively (figure not shown). Hence, the changes in diabatic heating during the recent decades can be regarded mainly as the change in deep-convection latent heating to some extent. Overall, these results derived from the reanalysis datasets indicate that diabatic heating has increased significantly due to the increased deep-convection latent heating in boreal spring. We further examine this result using observations of the climate variables associated with diabatic heating.

The increase in latent heating should be accompanied by more precipitation. We examine the changes in precipitation using the GPCP dataset. As shown in Fig. 2a, the trends of springtime precipitation exhibit large and significant positive values over the TWNP and the SCS, with a maximum exceeding $2.5\left[\mathrm{~mm} \mathrm{day}^{-1}(37 \text { year })^{-1}\right]$ near $4^{\circ}-10^{\circ} \mathrm{N} / 125^{\circ}-145^{\circ} \mathrm{E}$. The area-averaged positive trends over the TWNP (black dashed box) is about 1.2 $\left[\mathrm{mm} \mathrm{day}{ }^{-1}(37 \text { year })^{-1}\right]$, accounting for above $18 \%$ of the 37-year springtime climatological precipitation over this region. The increased precipitation is accompanied by an anomalous cyclonic circulation extending from the SCS to the Philippine Sea in the lower troposphere, which is a Gill-type response to the increased latent heating over the TWNP (Fig. 2a). The changes in satellite-derived OLR correspond well to those in precipitation, and are characterized by prominent decreases over the SCS and the TWNP with the largest value exceeding $20\left[\mathrm{~W} \mathrm{~m}^{-2}(37 \mathrm{year})^{-1}\right]$ over $6^{\circ}-10^{\circ} \mathrm{N} / 125^{\circ}-145^{\circ} \mathrm{E}$ (Fig. $2 \mathrm{~b}$ ), indicating a pronounced strengthening of deep convection. Although observational convection heating is always hard to obtain, the changes in observed precipitation and OLR both indicate increased springtime convection heating.

The western Pacific is known for the mean low-level convergence and heavy precipitation due to the existence of the warm pool and thus provides favorable conditions for amplifying the local atmospheric responses (Wang 2000). In addition, a large amount of moisture convergence occurs in the planetary boundary layer (PBL). Strengthening of the mean low-level convergence can easily induce local anomalous moisture convergence and resultant increase in precipitation, and vice versa. Consistent with the significantlyincreased precipitation, the mean convergence in the PBL has intensified over the TNWP during the recent decades (Fig. 2c). To better understand the changes in precipitation and its connection with the changes in convergence, we also calculate the changes in vertically-integrated moisture flux convergence (MFC). Approximately, the MFC is balanced
Fig. 2 MAM linear trends of a precipitation (shading; $\mathrm{mm}$ day $\left.^{-1}(37 \text { year })^{-1}\right)$, b outward longwave radiation (OLR; shading; $\left.\mathrm{W} \mathrm{m}^{-2}(37 \text { year })^{-1}\right)$, c low-level convergence (vertically averaged between 850 and $1000 \mathrm{hPa}$; shading; $10^{-6} \mathrm{~s}^{-1}$ $(37 \text { year })^{-1}$ ), and $\mathbf{d}$ the vertically integrated moisture flux convergence (MFC) (shad-

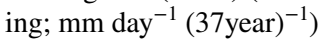
for 1979-2015. Dashed box indicates the TWNP region. Vectors in a indicate $850-\mathrm{hPa}$ wind, showing only areas of $>$ $90 \%$ confidence level. Stippling indicates the significant values above the $90 \%$ confidence level. Gray hatching denotes where the moisture convergence of dynamic components $\left[\int_{p_{t}}^{p_{s}} q_{c l m} \nabla \cdot \delta \bar{V}\right]$ takes up more than $80 \%$ of the MFC change (a) MAM Precip\& 850UV trend

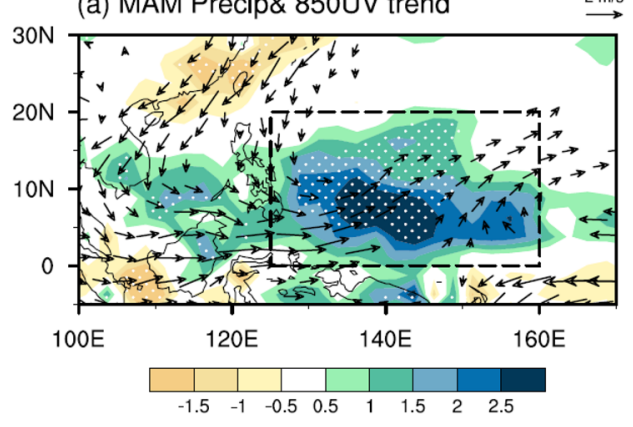

(c) MAM low-level convergence trend

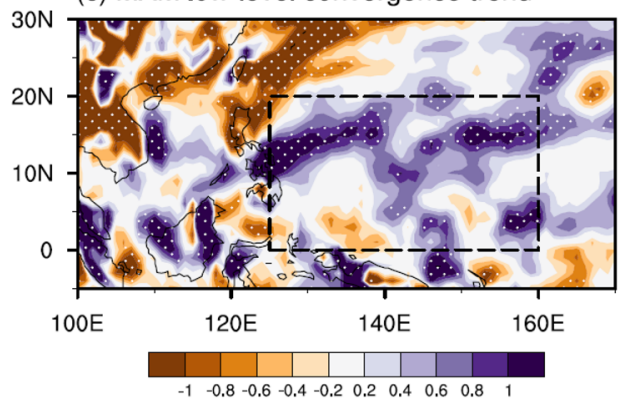

(b) MAM OLR trend

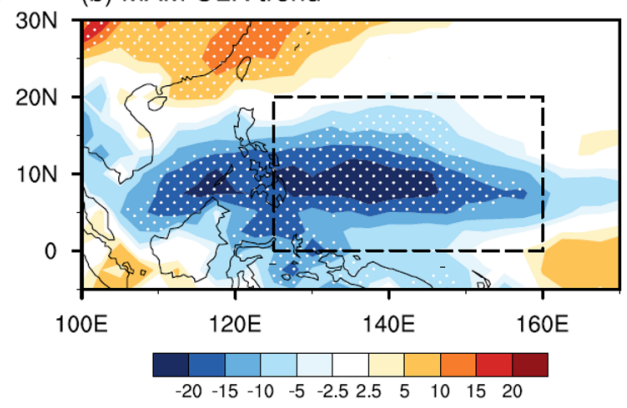

(d) MAM MFC Trend

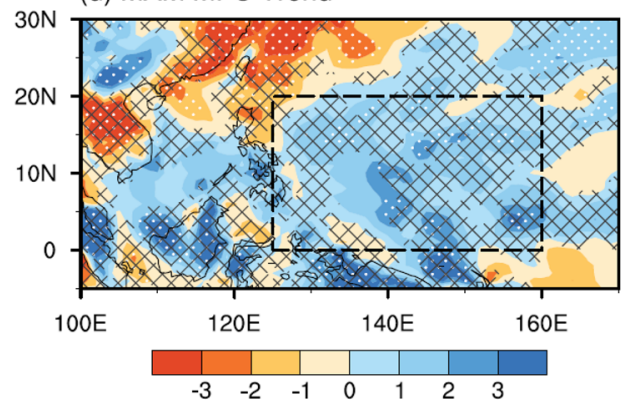


by precipitation minus evaporation in the moisture budget equation:

$\bar{P}-\bar{E} \approx-\nabla \cdot \bar{Q}=-\frac{1}{g} \int_{p_{t}}^{p_{s}} \nabla \cdot(q \bar{V}) d p$,

where $P$ is precipitation and $E$ evaporation. $-\nabla \cdot Q$ represents the MFC, $q$ is specific humidity, $V$ is the horizontal wind vector, $p_{s}$ is surface pressure $(1000 \mathrm{hPa}), p_{t}$ is top pressure $(0 \mathrm{hPa})$, and $\mathrm{g}$ is the acceleration of gravity. In this study, () indicates the time average in boreal spring (MAM). The changes in MFC are important to precipitation changes since precipitation reacts to MFC change (Kim and Ha 2015; $\mathrm{Li}$ et al. 2016b). As shown in Fig. 2d, MFC increases prominently over the TWNP in boreal spring. Besides, the trend of MFC exhibits a similar spatial pattern to that of precipitation change, with regions of enhanced (suppressed) MFC corresponding to the regions of increased (decreased) precipitation, such as over the TWNP and the SCS. Therefore, the changes in MFC generally illustrate those in precipitation over the TWNP. Following Seager et al. (2010), the change in the MFC can be decomposed into terms as follows:
In the other seasons, the trends of precipitation are generally smaller than those in the boreal spring, and are insignificant over most of the TWNP (Fig. 3a, d, g). To examine the robustness of the seasonality of precipitation change, we also calculate the linear trends of precipitation for all seasons using the CMAP dataset. The changes in CMAP precipitation over TNWP also show a notable seasonality with a remarkable increase in boreal spring and smaller changes in the other seasons (figure not shown). Corresponding to the precipitation changes, the anomalous cyclonic circulation that appears in spring $\left(0^{\circ}-20^{\circ} \mathrm{N} / 110^{\circ}-145^{\circ} \mathrm{E}\right.$ in Fig. 1a) does not occur in these seasons. Instead, notable anticyclonic anomalies emerge over the regions from the SCS to the western TWNP $\left(0^{\circ}-20^{\circ} \mathrm{N} / 110^{\circ}-130^{\circ} \mathrm{E}\right)$ in boreal summer and autumn (Fig. 3a, d). Consistently, the deep convection changes over the TWNP are insignificant in these seasons (Fig. 3b, e, h). Moreover, anomalous low-level divergence emerges over most of the TWNP and the SCS in these seasons (Fig. 3c, f, i), corresponding to the anomalous anticyclone at $850 \mathrm{hPa}$.

Therefore, by analyzing the changes in diabatic heating derived from the reanalysis datasets and the associated atmospheric variables from observations, we reveal that the

$-\delta(\nabla \cdot \bar{Q}) \approx-\left[\frac{1}{g} \int_{p_{t}}^{p_{s}}\left(\delta \bar{q} \nabla \cdot \bar{V}_{c l m}+\bar{q}_{c l m} \nabla \cdot \delta \bar{V}+\delta \bar{V} \cdot \nabla \bar{q}_{c l m}+\bar{V}_{c l m} \cdot \nabla \delta \bar{q}\right) d p\right]-\left[\frac{1}{g} \int_{p_{t}}^{p_{s}} \nabla \cdot \delta\left(\overline{q^{\prime} V^{\prime}}\right) d p\right]$

where $\delta$ denotes the linear change (estimated by the linear trend during 1979-2015), clm denotes the MAM climatology, and() indicates the MAM averages. Deviations from the MAM averages are denoted by primes. The terms involving changes in $V$ but no changes in $q$ are referred to as the dynamic components and those involving changes in $q$ but no changes in $V$ are the thermodynamic components. Quantitatively, the enhancement of MFC over the TWNP is mainly dominated by the moisture convergence of dynamic components, i.e. [ $\left.\int_{p_{t}}^{p_{s}} \bar{q}_{c l m} \nabla \cdot \delta \bar{V} d p\right]$. Indeed, the $\left[\int_{p_{t}}^{p_{s}} \bar{q}_{c l m} \nabla \cdot \delta \bar{V} d p\right]$ term makes more than $80 \%$ contribution to the increased MFC over most of the TWNP (Gray hatching in Fig. 2d). Furthermore, $\left[\int_{p_{t}}^{p_{s}} \bar{q}_{c l m} \nabla \cdot \delta \bar{V} d p\right]$ is mainly induced by the enhanced low-level convergence $(1000-850 \mathrm{hPa})$, which accounts for $80 \%$ of the total value, while the convergence change above $850 \mathrm{hPa}$ (i.e. $\int_{0}^{850} q_{c l m}^{-} \nabla \cdot \delta V d p$ ) only accounts for $20 \%$. This result indicates that enhanced low-level convergence plays a dominant role in increasing precipitation over TWNP. Thus, the anomalous cyclonic circulation, which is probably a Rossby wave response to the increased heating (Fig. 2a), may in turn promote the increase in rainfall via convergence (Fig. 2d). A positive feedback between anomalous heating and low-level convergence is thus established over the TWNP region. diabatic heating over the TWNP has increased in the boreal spring, caused by the increased convectional latent heating. By contrast, the changes in diabatic heating in other seasons are very small, due to the insignificant changes in deep convection.

\section{Influence of local SST warming on deep convection changes}

We now explore the influence of recent local SST changes on deep convection changes over the TWNP. The long-term trends of SST over the western North Pacific for 1979-2015 are shown in Fig. 4. Clearly, SST has increased significantly in the TWNP for all seasons. Also, the spatial distribution of SST trends shows a similar warming pattern in the TWNP, characterized by the maximum values near the equator and along $130^{\circ}-150^{\circ} \mathrm{E}$. The magnitude of SST warmings is similar among all four seasons, with area-averaged values of about $0.44{ }^{\circ} \mathrm{C}$ for MAM, $0.38{ }^{\circ} \mathrm{C}$ for JJA, $0.37{ }^{\circ} \mathrm{C}$ for SON, and $0.44{ }^{\circ} \mathrm{C}$ for DJF. The climatological SSTs over the TWNP are also shown in Fig. 4 (contours). During the boreal spring and winter, the SSTs are all below 29 ${ }^{\circ} \mathrm{C}$, with a range of $27.5-29^{\circ} \mathrm{C}$ (Fig. $4 \mathrm{a}$, d), whereas the 


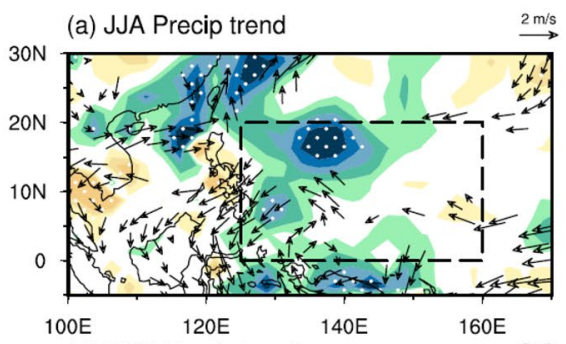

(b) JJA OLR trend

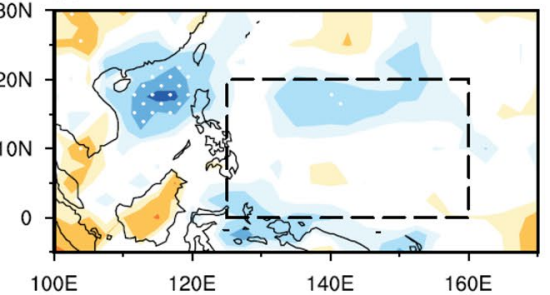

(e) SON OLR trend

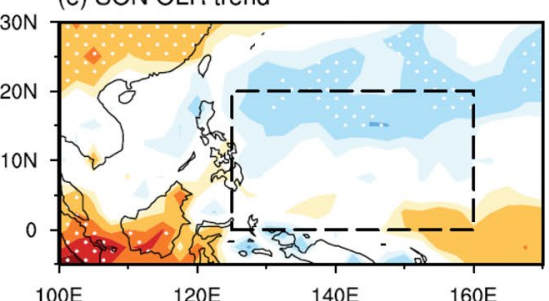

(h) DJF OLR trend

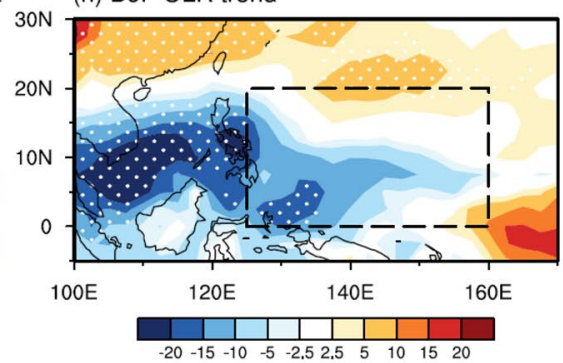

(c) JJA low-level convergence trend

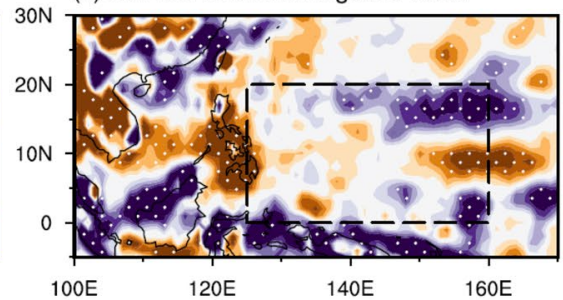

(f) SON low-level convergence trend

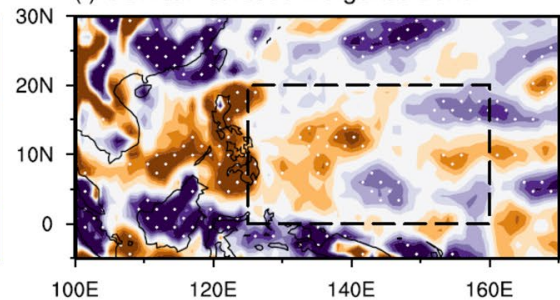

(i) DJF low-level convergence trend

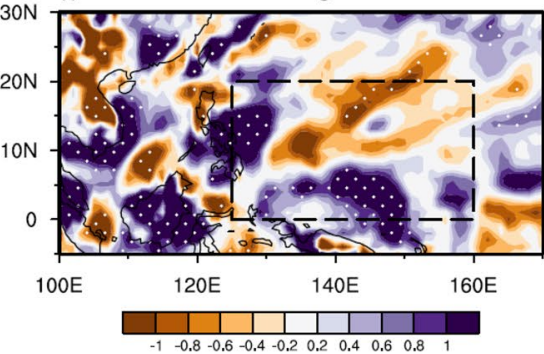

Fig. 3 Linear trends of a JJA, d SON, g DJF precipitation (shading; $\mathrm{mm} \mathrm{day}{ }^{-1}\left(37\right.$ year $\left.^{-1}\right)$; b, e, $\mathbf{f}$ outward longwave radiation (OLR) (shading; $\mathrm{W} \mathrm{m}^{-2}$ (37year) $\left.^{-1}\right)$; and $\mathbf{c}, \mathbf{f}, \mathbf{i}$ low-level convergence (shad- ing; $\left.10^{-6} \mathrm{~s}^{-1}(37 y e a r)^{-1}\right)$ for 1979-2015. Dashed box indicates the TWNP region. Stippling indicates the significant values above the $90 \%$ confidence level
Fig. 4 Linear trends (shading; units: ${ }^{\circ} \mathrm{C}(37 \text { year })^{-1}$ ) and climatology (contour; units: ${ }^{\circ} \mathrm{C}$ ) of SST over the western North Pacific during 1979-2015, for seasonal means of a MAM, b JJA, c SON, and d DJF. Dashed box indicates the TWNP region. Stippling indicates the significant values above the $99 \%$ confidence level (a) MAM SST trend

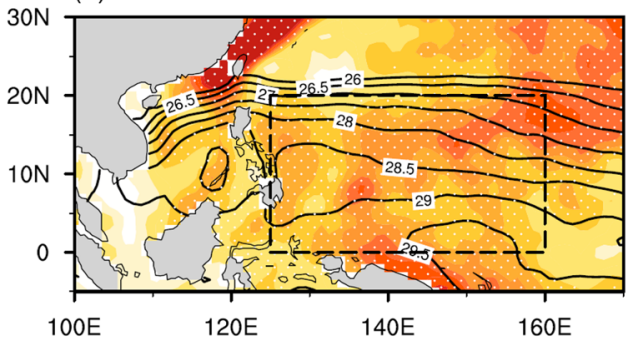

(c) SON SST trend

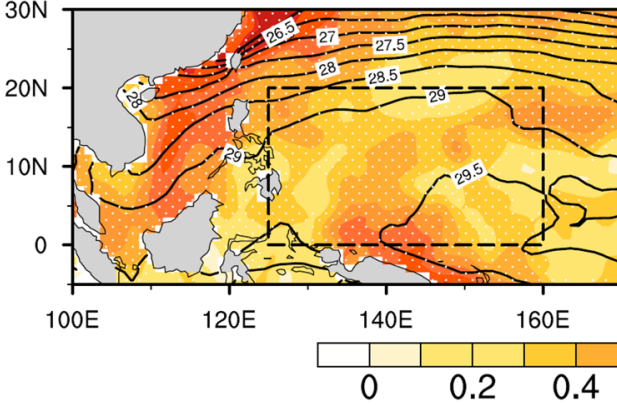

(b) JJA SST trend

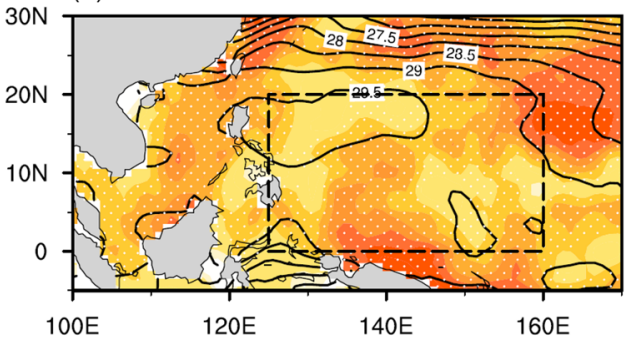

(d) DJF SST trend

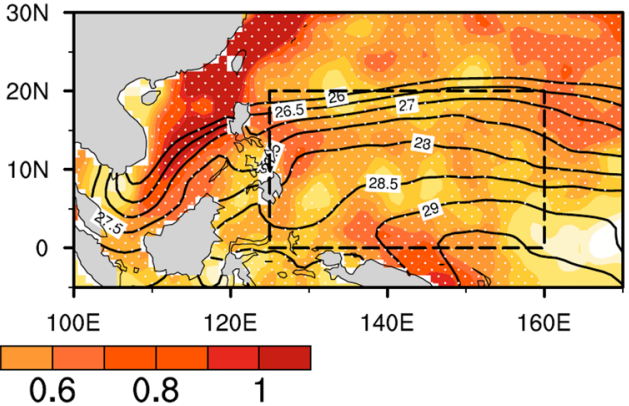


climatological SSTs during summer and autumn exceed 29 ${ }^{\circ} \mathrm{C}$ in most of the TWNP, with higher values of $29-29.5^{\circ} \mathrm{C}$ (Fig. 4b, c).

To understand the response of TWNP convection to local SST warming, we examine the relationship between convection and SST. Given that the convection-SST relationship exhibits remarkable regional features in the Pacific Ocean (Lau et al. 1997; Sabin et al. 2013), we only focus on the TWNP. Figure 5a shows a scatterplot of colocated SST and OLR grid-point values based on monthly data. All data are detrended and filtered using a 3-month running mean filter to focus on seasonal time scales. The OLR has a large scatter in each SST bin, especially when SST is high. These scatters indicate the inherent temporal and spatial variabilities of deep convection, which are not matched by the SST variations, but mainly modulated by other factors such as low-level convergence (Graham and Barnett 1987; Zhang 1993; Lau et al. 1997). The influence from other factors can be eliminated to some extent by averaging OLR in each SST bin. The mean OLR (OLR*, the blue curve in Fig. 5a) can thus be roughly considered as the portion that depends on SST alone (Lau et al. 1997; Xie et al. 2020). Hence, the convection-SST relationship is represented by the blue curve that connects OLR ${ }^{*}$. The SST-induced convection intensifies monotonically as SST rises from $26.5{ }^{\circ} \mathrm{C}$ to $29.75{ }^{\circ} \mathrm{C}$ and soars around 28 ${ }^{\circ} \mathrm{C}$ in particular. It then peaks when SST reaches about $29.75{ }^{\circ} \mathrm{C}$, but declines slightly at higher SST (Fig. 5a). This nonlinear convection-SST relationship is generally similar to that reported previously (Waliser and Graham 1993; Lau et al. 1997; Sabin et al. 2013; Xie et al. 2020). However, differences are also apparent. For instance, the SST range in which convection intensifies monotonically with increasing SST is $25.25-30.25^{\circ} \mathrm{C}$ in Xie et al. (2020). This difference can be attributed to the different analysis regions used. We emphasize on the TWNP region, while Xie et al. (2020) focused on the whole tropics. It should also be pointed out that the convection-SST relationship for SSTs above $29.5^{\circ} \mathrm{C}$ (Fig. 5a) is inconsistent with that in Roxy (2014), who found that deep convection still increased with increasing SST for very high SSTs. This inconsistency can be attributed to the different time scales (a) OLR and SST

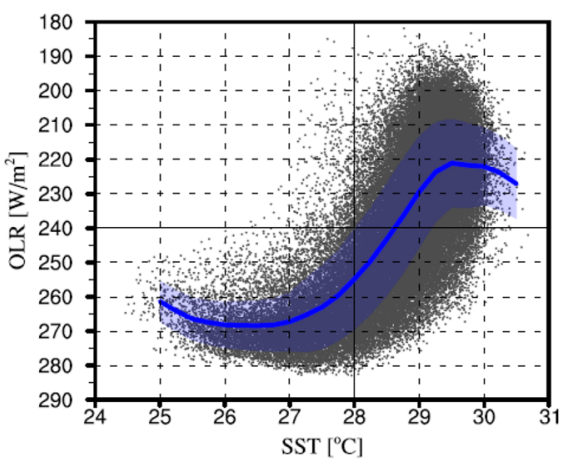

(d) $\partial(\mathrm{OLR}) / \partial(\mathrm{SST})$ from (a)

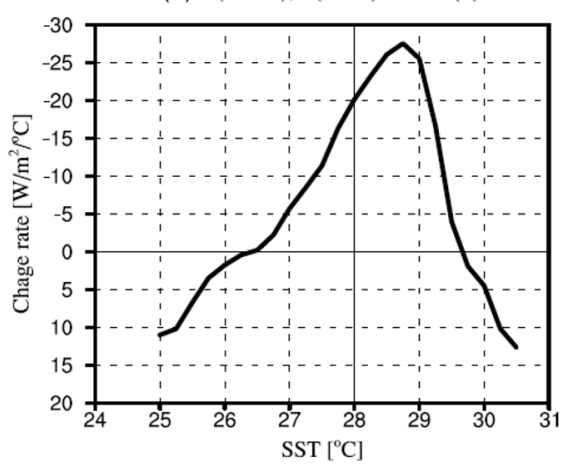

(b) OLR and Conv

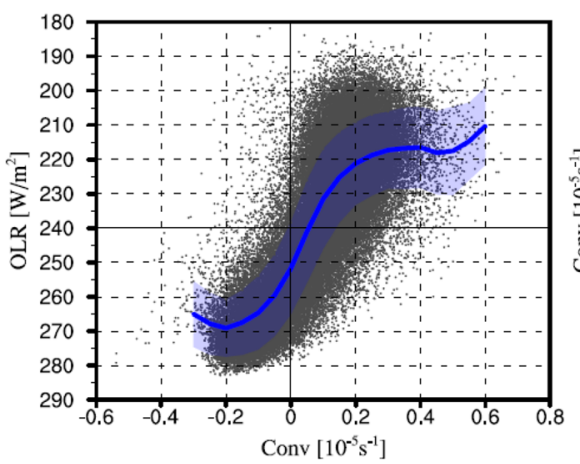

(e) $\partial($ OLR $) / \partial($ Conv) from (b)

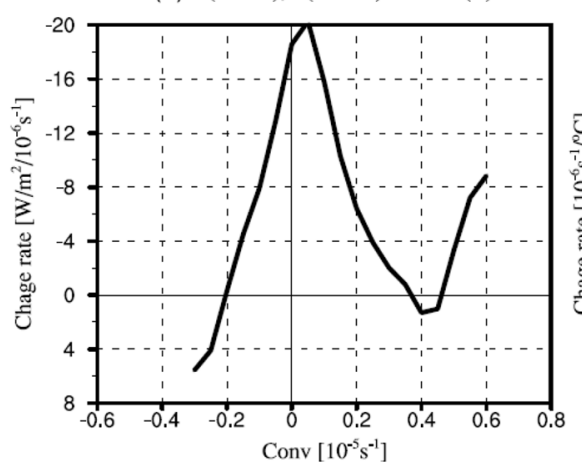

(c) Conv and SST

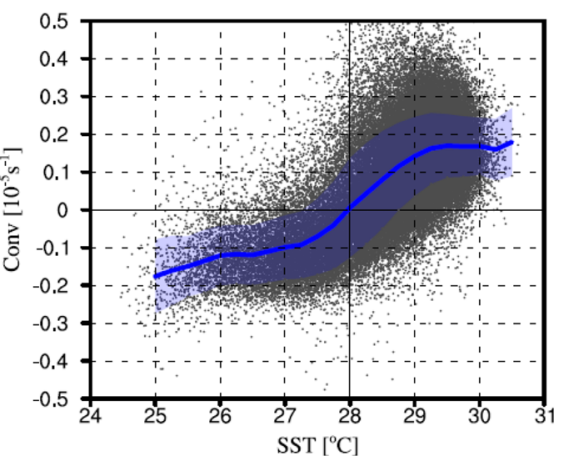

(f) $\partial($ Conv $) / \partial($ SST $)$ from (c)

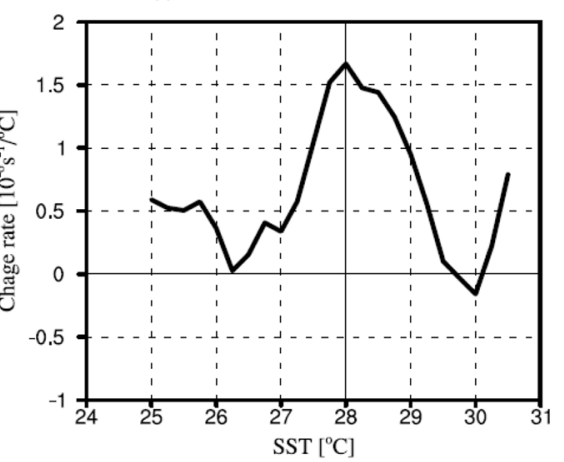

Fig. 5 Relationships of SST and convection (indicated by OLR), low-level convergence (Conv; vertically averaged between 850 and $1000 \mathrm{hPa}$ ) and convection, and of SST and low-level convergence in the TWNP region. Scatterplots of a OLR and SST, $\mathbf{b}$ OLR and Conv, and $\mathbf{c}$ Conv and SST. Blue lines in $\mathbf{a}, \mathbf{b}, \mathbf{c}$ denote mean OLR in each $0.25{ }^{\circ} \mathrm{C}$ SST bin, mean OLR in each $10^{-6} \mathrm{~s}^{-1} \mathrm{Conv}$ bin, and mean convergence in each $0.25{ }^{\circ} \mathrm{C}$ SST bin, respectively. Blue shading indicates \pm 1 standard deviations with respect to the mean in each bin. d Sensitivity of OLR to SST. e, f Same as d, but for the sensitivity of OLR to convergence and the sensitivity of convergence to SST, respectively. All monthly data are detrended and filtered using a 3-month running mean filter 
analyzed. Roxy (2014) showed that the precipitation-SST correlation derived from daily data was not instantaneous but with a lag of several days or even weeks. The precipitation would not be reduced with increasing SST for very high SSTs after considering the lag relationship, because strong positive correlations are still observed when SST leads at high SSTs. However, as argued by Wu (2019), the time-lag relationship between precipitation and SST variations depends upon time scales. Precipitation and SST variations in the Philippine Sea exhibit obvious time lags on intraseasonal (period of 10-90 days) and synoptic time scales (period shorter than 10 days) but not on interannual (longer than 90 days) time scale. Since monthly data excludes most high-frequency variations, the lag relationship thus becomes weaker and the simultaneous relation becomes stronger. Given that we aim to investigate the impact of seasonal mean SST warming on deep convection changes, the simultaneous convection-SST relationship quantified from monthly data is more suitable. In summary, OLR ${ }^{*}$ indicates the relationship between convection and SST: increased SST in the $26.5-29.75{ }^{\circ} \mathrm{C}$ range can enhance convection. Moreover, the slope of the OLR ${ }^{*}$ curve is quite steep around $28^{\circ} \mathrm{C}$, implying very high sensitivity of convection to SST.

Following Xie et al. (2020), the convection sensitivity to SST at each $0.25{ }^{\circ} \mathrm{C} \mathrm{SST}$ bin is expressed as follows:

$\frac{\partial O L R^{*}}{\partial T}=\frac{O L R^{*}(T+\Delta T)-O L R^{*}(T-\Delta T)}{2 \Delta T}$

where $\Delta T$ is $0.25{ }^{\circ} \mathrm{C}$. A negative value of $\frac{\partial O L R^{*}}{\partial T}$ denotes a positive tendency of convection intensity with SST (i.e. positive sensitivity). As shown in Fig. 5d, the convectionSST sensitivity also shows strong nonlinearity. Specifically, positive sensitivity occurs and increases with rising SST when SST exceeds $26.5^{\circ} \mathrm{C}$, and reaches a maximum when SST is at $28.75{ }^{\circ} \mathrm{C}$; whereas it decreases with rising SST at SSTs beyond $28.75{ }^{\circ} \mathrm{C}$ (Fig. 5d). Because convection is also strongly dependent on low-level convergence, the decreasing convection-SST sensitivity with increasing SST at SST $>28.75{ }^{\circ} \mathrm{C}$ indicates that wind convergence may exert a larger impact on convection. The relationship between convection and low-level convergence is also established by sorting OLR as a function of convergence. In each $10^{-6} \mathrm{~s}^{-1}$ convergence bin, OLR is sorted and mean OLR values are calculated (Fig. 5b). The intensity of convection also rises monotonically with the strengthening of low-level convergence. Nevertheless, unlike the convection-SST relationship, the relationship between OLR and convergence appears to be quite monotonic. Convection still intensifies with strengthening convergence under the condition of strong convergence. Note that convection intensity soars when the low-level convergence starts to appear (Fig. 5b). The OLR-convergence sensitivity thus exhibits the highest value when convergence occurs (Fig. 5e).

We should point out that convergence itself is also dependent on SST distribution and is strongly driven by SST gradient (Lindzen and Nigam 1987). In each $0.25{ }^{\circ} \mathrm{C}$ SST bin, low-level convergence is sorted and averaged to represent the relationship between convergence and SST. Convergence enhances monotonically with increasing SST, and intensifies sharply around $28{ }^{\circ} \mathrm{C} \mathrm{SST}$. Besides, the low-level wind starts to converge when SST exceeds $28{ }^{\circ} \mathrm{C}$ (Fig. 5c), corresponding to the highest convergence-SST sensitivity (Fig. 5f). Therefore, the warm SST around $28^{\circ} \mathrm{C}$ can enhance convergence significantly, and then works together with the enhanced convergence to reinforce convection. Such a SST dominant position in the relationships among SST, convection, and convergence leads to quite high convection-SST sensitivity at the SST around $28^{\circ} \mathrm{C}$. For instance, in the SST range of $28-29{ }^{\circ} \mathrm{C}$, the convection-SST sensitivity is very high (Fig. 5d), with a mean value of about $-23 \mathrm{~W} \mathrm{~m}^{-2}{ }^{\circ} \mathrm{C}^{-1}$. We thus speculate that the TWNP convection is sensitive to the SST changes in boreal spring and winter due to the climatological SSTs in the range of $28-29{ }^{\circ} \mathrm{C}$ in most TWNP regions. However, when SST is above $29{ }^{\circ} \mathrm{C}$, convergence is hardly enhanced as local SST increases (Fig. 5c). Meanwhile, the convection-SST sensitivity decreases sharply with increasing SST (Fig. 5d). Over such high SST, the local SST is likely to lose the key role in modulating convergence and convection. In this situation, the convergence induced by remotely forced changes in vertical motion or atmospheric stability may play a more dominant role in governing convection (Graham and Barnett 1987; Lau et al. 1997). Based on the above statistical analysis, the SST around $28{ }^{\circ} \mathrm{C}$ exerts a large impact on convection and convergence, which may provide us a reliable statistical explanation of considering 28 ${ }^{\circ} \mathrm{C}$ as the SST threshold for deep convection over the TWNP.

As seen in Fig. 5a and d, SST has the potential to generate convection in the range of $26.5-29.75^{\circ} \mathrm{C}$. The convectionSST sensitivity in this range is thus defined as the efficiency of SST (EOT) in generating convection following the method in Xie et al. (2020),

$\operatorname{EOT}(T)= \begin{cases}\frac{\partial O L R^{*}}{\partial T} \cong\left\{\begin{array}{l}-13.1 T+348.0,26.5 \leq T \leq 28.75^{\circ} \mathrm{C} \\ 32.2 T-956.4,28.75 \leq T \leq 29.75^{\circ} \mathrm{C}\end{array}\right. \\ 0 \quad \text { otherwise }\end{cases}$

Beyond the SST range of $26.5-29.75{ }^{\circ} \mathrm{C}$, the EOT is set to zero. The convection-SST sensitivity in the SST range of 26.5-29.75 ${ }^{\circ} \mathrm{C}$ can be expressed as quasi-linear piecewise functions. To estimate SST warming-induced OLR changes during the recent decades, we integrate the EOT with respect to SST as follows: 
Fig. 6 Local SST warminginduced changes in OLR (i.e. COLR as defined in Eq. (5)) (shading; $\mathrm{W} \mathrm{m}^{-2}$ (37year) $^{-1}$ ) over the western North Pacific for seasonal means of a MAM, b JJA, c SON, and d DJF. Climatological SSTs for corresponding seasons are shown as contours (units: ${ }^{\circ} \mathrm{C}$ ). Dashed box indicates the TWNP region. Stippling indicates SST warming trend significant at the $99 \%$ confidence level (a) MAM SST warming-induced OLR change

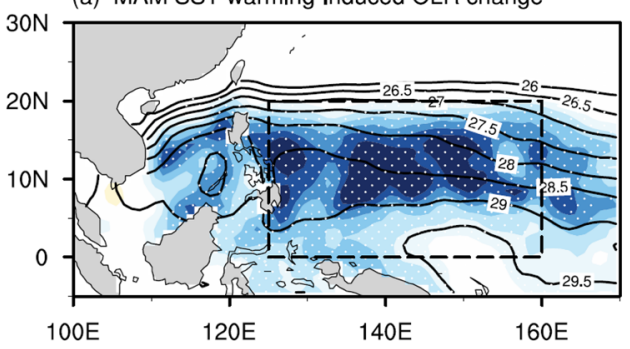

(c) SON SST warming-induced OLR change

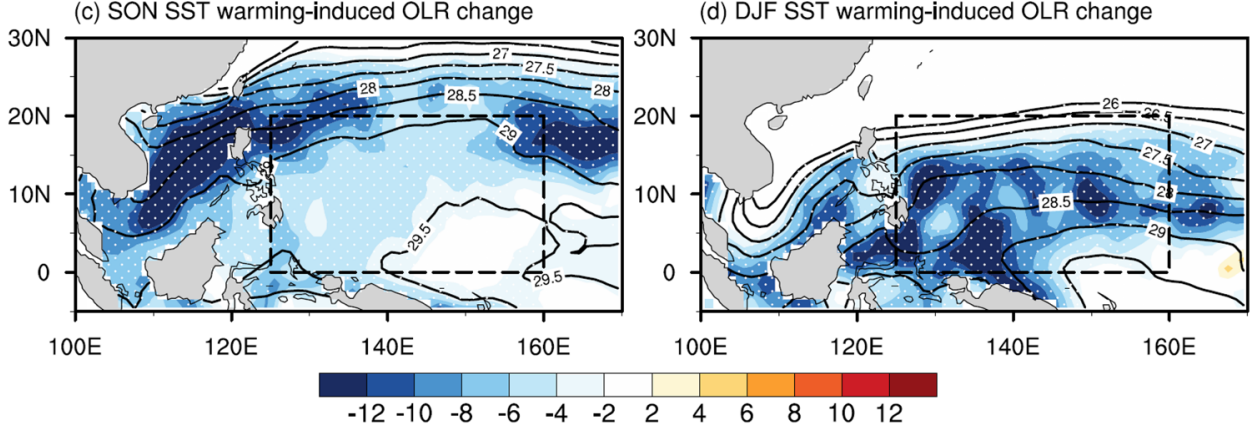

(b) JJA SST warming-induced OLR change

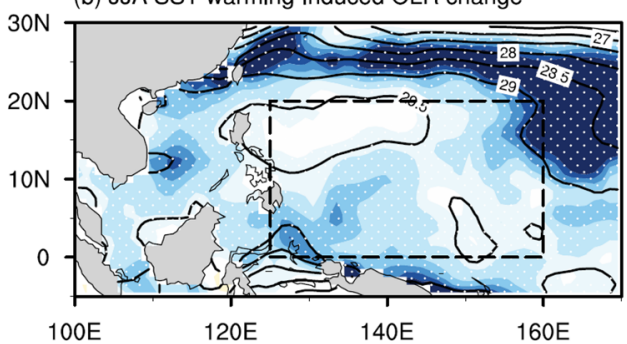

(d) DJF SST warming-induced OLR change
COLR $=\int_{T_{m}}^{T} E O T(T) d T$

where COLR denotes SST-induced OLR change, which is the same as the change in OLR ${ }^{*}$ in the SST range of 26.5-29.75 ${ }^{\circ} \mathrm{C} . T_{m}$ is the climatological SST; and $T$ is the climatology SST plus 37-year linear SST change, that is, $T=T_{m}+$ SST change. According to Eqs. (4) and (5), we integrate $\operatorname{EOT}(T)$ from $T_{m}$ to $T$ to quantify SST warminginduced OLR change. The COLR at each grid in the western North Pacific is shown in Fig. 6 for all four seasons. Recent SST warming can cause a substantial reduction in OLR over the TWNP. Because high convection-SST sensitivity exists in the SST range of $28-29{ }^{\circ} \mathrm{C}$, it is not surprising that the largest reduction of OLR is located at $4^{\circ}-13^{\circ} \mathrm{N} / 125^{\circ}-155^{\circ} \mathrm{E}$ (Fig. 6a), where the climatological SSTs are in the range of $28-29{ }^{\circ} \mathrm{C}$. In addition, the spatial distribution of SSTinduced OLR changes (Fig. 6a) is quite similar to that of the observed OLR change (Fig. 2b). Quantitatively, the areaaveraged OLR change induced by SST warming is about $-8.79 \mathrm{~W} \mathrm{~m}^{-2}$ (37year) $^{-1}$, which can explain about $72 \%$ of the observed OLR change $\left(-12.2 \mathrm{~W} \mathrm{~m}^{-2}(37 \text { year })^{-1}\right)$. Thus, local SST warming plays a dominant role in the observed enhancement of springtime deep convection. The residual signal may include the contribution from wind convergence. By contrast, the SST warming-induced OLR changes are much smaller in summer and autumn than those in spring (Fig. 6b, c), although the increases of SST in summer and autumn are comparable to those in spring. This is because the climatological SSTs in summer and autumn are both in the range of $29-29.5^{\circ} \mathrm{C}$, in which convection-SST sensitivity is lower than that in the range of $28-29^{\circ} \mathrm{C}$. Note that the magnitude of SST warming-induced OLR change in the boreal winter is also large and comparable to that in spring, with an area-averaged value of $-9.05 \mathrm{~W} \mathrm{~m}^{-2}$ (37year) $^{-1}$ (Fig. 6d).

Based on the above analysis, we find that the observed enhancement of springtime deep convection over the TWNP is mainly caused by local SST warming. Besides, local SST warming can also significantly intensify the deep convection in other seasons, although the magnitude is relatively small, especially in summer and autumn (Fig. 6b, c). However, significant enhancements of deep convection cannot be detected in the observations for those seasons except the spring (Fig. 3b, e, h), despite the presence of SST warming. These observed trends imply that other factors exert negative impacts on convection and cancel the positive effect from local SST warming. Moreover, anomalous low-level divergence occurs over most of the TWNP in those seasons (Fig. 3c, f, i). Since local SST warming cannot physically cause the anomalous low-level divergence, it may be argued that these changes are remotely induced. We speculate that the SST warming over the TIO is a likely candidate, which is discussed next.

\section{Impact of recent TIO warming on TWNP convection}

Figure 7 shows the linear trends of SSTs over the tropical oceans for four seasons. The general spatial distributions of SST trends resemble each other among the four 
seasons, with a pan-tropical dipole-like pattern. SSTs are warm over the tropical Atlantic and Indo-western Pacific, but cool over the eastern Pacific. Some differences among the seasons, however, can be found from the perspective of regional distributions such as the distinct difference in TIO SST trends between spring (Fig. 7a) and the other seasons (Fig. 7b, c, d). TIO warming is quite modest in spring compared to the other seasons, with an area-averaged $\left(40^{\circ}-110^{\circ} \mathrm{E} / 20^{\circ} \mathrm{S}-20^{\circ} \mathrm{N}\right)$ value of $0.29 \mathrm{k}(37 \text { year })^{-1}$, which is $32 \%, 55 \%$, and $42 \%$ less than the value of summer $\left(0.39 \mathrm{k}(37 \text { year })^{-1}\right)$, autumn $\left(0.45 \mathrm{k}(37 \text { year })^{-1}\right)$, and winter $\left(0.42 \mathrm{k}(37 \text { year })^{-1}\right)$, respectively. We also analyze the NOAA Extended Reconstructed SST V4 (ERSST4; Huang et al. 2015) and Centennial in situ ObservationBased Estimates (COBE) SST data (Folland and Parker 1995), both of which show roughly consistent SST trends as the HadISST data with modest TIO SST warming in boreal spring (figure not shown). Because the interannual variation of the TIO SST is closely associated with El Niño-Southern Oscillation (ENSO) and the impact of ENSO on TIO SST exhibits a seasonal dependence (Xie et al. 2016), ENSO signals may affect the seasonality of TIO SST trends to some extent. Nevertheless, it is also confirmed that the seasonality of recent TIO warming is still robust after removing the ENSO effect using the linear regression with respect to the Niño 3.4 index (figure not shown). Thus, the linear trends of TIO SST indeed show a seasonality during the recent decades.

To reveal the changes in precipitation, wind, and convection associated with the recent TIO warming, following Thompson et al. (2000), we divide the observed trends of precipitation, wind, and OLR into linearly congruent and linearly independent components with respect to the TIO SST (TIOST: area-averaged over $40^{\circ}-110^{\circ} \mathrm{E} / 20^{\circ} \mathrm{S}-20^{\circ} \mathrm{N}$ ). The linearly congruent component of each season is estimated at each grid by first regressing the seasonal mean and detrended time series onto the corresponding seasonal mean TIOST and then multiplying the linear trend of the TIOST (see the "Appendix"). Note that ENSO signals have been removed from the time series of atmospheric variables and TIOST before the linear congruency is calculated.

Figure 8 shows the linear congruency of precipitation, $850-\mathrm{hPa}$ wind, and OLR trends with TIOST. In boreal spring, the precipitation and convection changes linked to TIO warming are weak over the TIO (Fig. 8a, b). Meanwhile, no significant wind changes can be found over the whole Indo-Pacific region, except the western Indian Ocean where westerly anomalies appear (Fig. 8a). In sharp contrast, a prominent increase in rainfall occurs over the western TIO in the other seasons (Fig. 8c, e, g), which is consistent with the notable reductions in OLR (Fig. 8d, f, h). Besides, the anomalous easterly winds prevail in the lower troposphere over the eastern equatorial Indian Ocean, SCS, and TWNP (Fig. 8c, e, g), which are probably induced by the Kelvin wave in response to the latent heating anomalies over the TIO.

Note that in all the seasons except spring, notably negative rainfall and convection anomalies appear over the SCS and the TWNP associated with the TIO warming (Fig. $8 \mathrm{c}-\mathrm{h}$ ), accompanied by an anomalous anticyclonic circulation. This feature indicates that TIO warming exerts a great negative impact on deep convection, which is based on the Kelvin wave induced Ekman divergence mechanism (Wu et al. 2009; Xie et al. 2009; Li et al. 2017). In the SCS and TNWP regions, the anomalous Kelvin wave easterly winds reach a maximum at the equator of the western Pacific and then decrease with latitude (Fig. 8c, e, g), inducing the anticyclonic wind shear and resultant boundary-layer divergence through Ekman pumping. The boundary-layer wind divergence and associated anomalous subsidence at the top of the PBL suppress deep convection. We also analyze the component of low-level divergence trend, which is linearly congruent with the TIOST (figure not shown). Quantitively, in all the seasons except spring, the TIO warming induced (a) MAM SST trend

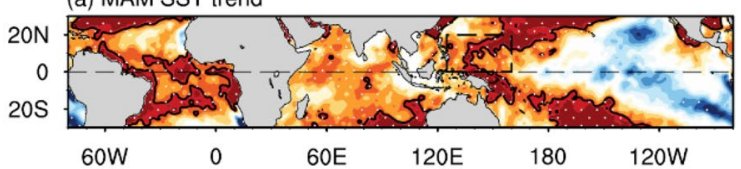

(c) SON SST trend

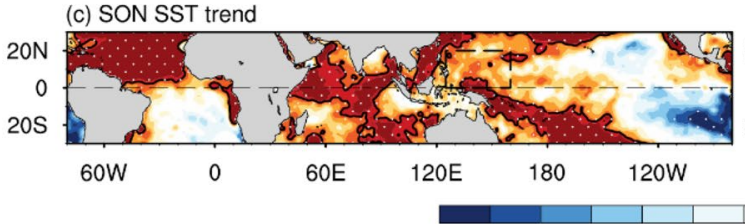

(b) JJA SST trend

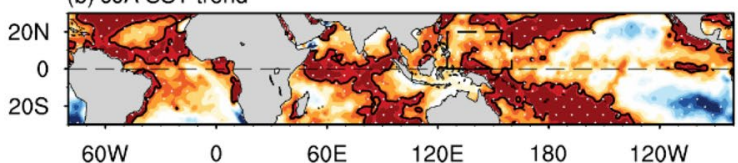

(d) DJF SST trend

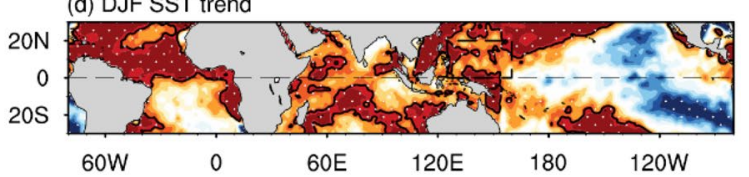

$\begin{array}{llllllllllll}-0.6 & -0.5 & -0.4 & -0.3 & -0.2 & -0.1 & 0.1 & 0.2 & 0.3 & 0.4 & 0.5 & 0.6\end{array}$

Fig. 7 Linear trends of SST (shading; $\mathrm{K}\left(37\right.$ year) ${ }^{-1}$ ) over the tropical ocean during 1979-2015 for seasonal means of a MAM, b JJA, c SON, and d DJF. Black contour denotes $0.5 \mathrm{~K}(37 \text { year })^{-1}$. Dashed box indicates the TWNP region. Stippling indicates the significant values above the $99 \%$ confidence level 
Fig. 8 Linear congruency of a MAM, c JJA, e SON, and g DJF precipitation (shading; $\left.\mathrm{mm} \mathrm{day}^{-1}(37 \text { year })^{-1}\right), 850-\mathrm{hPa}$ wind (vector; $\mathrm{m} \mathrm{s}^{-1}\left(37\right.$ year) ${ }^{-1}$ ) trends with corresponding seasonal mean tropical Indian Ocean SST index (TIOST; areaaveraged SST over $40^{\circ}-110^{\circ} \mathrm{E}$, $\left.20^{\circ} \mathrm{S}-20^{\circ} \mathrm{N}\right) . \mathbf{b}, \mathbf{d}, \mathbf{f}, \mathbf{h}$ Same as $\mathbf{a}, \mathbf{c}, \mathbf{e}, \mathbf{g}$, but for OLR (shading; $\left.\mathrm{W} \mathrm{m}^{-2}(37 \text { year })^{-1}\right)$. Dashed box indicates the TWNP region. Stippling indicates the $90 \%$ confidence level. Only wind vectors with the significant values above the $90 \%$ confidence level are plotted
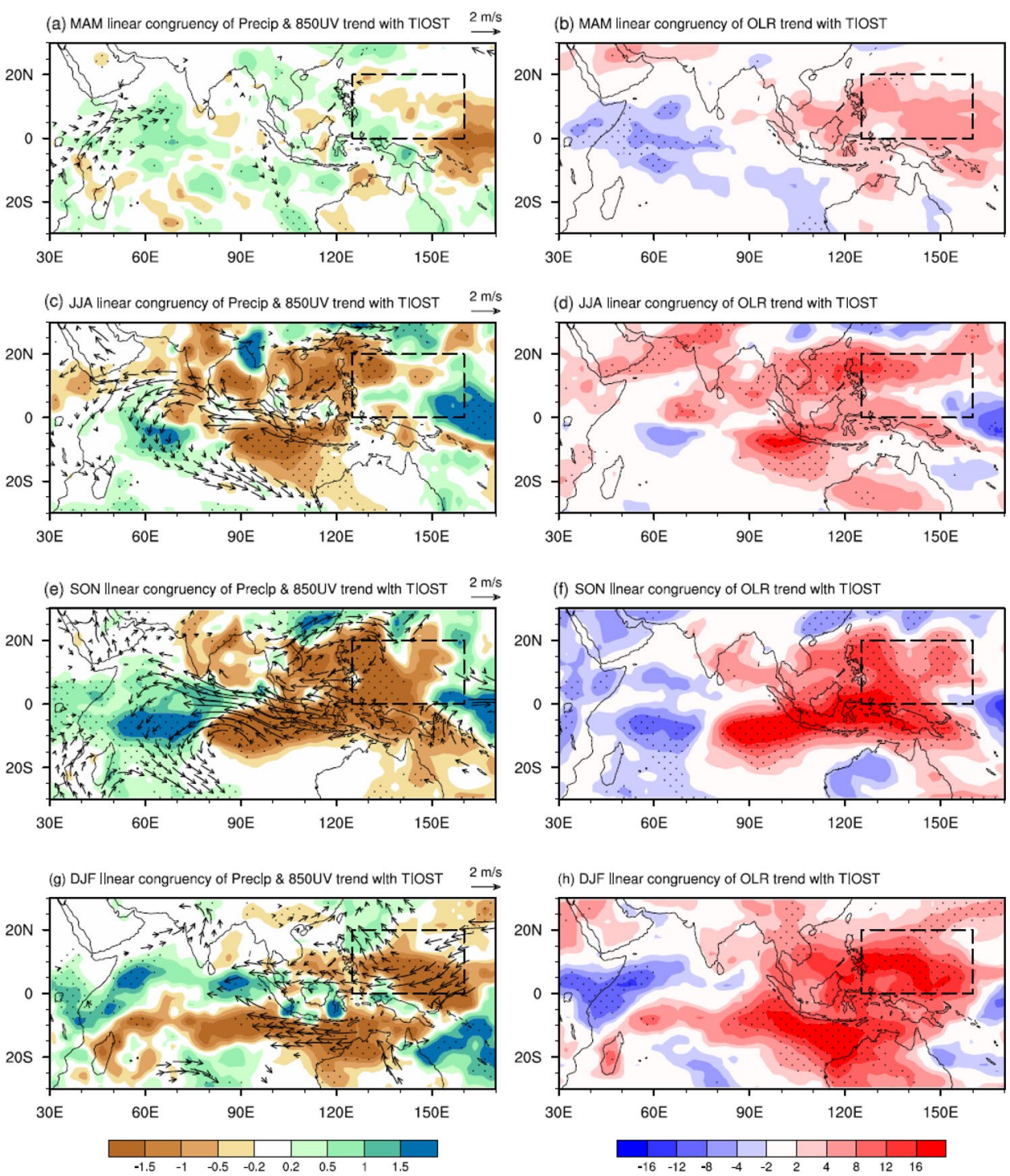

low-level divergence anomalies can explain more than $70 \%$ of the observed divergence trends over most TWNP regions, indicating the dominant role of TIO warming in inducing the observed divergence trends (Fig. 3c, f, i). Overall, we can infer that the springtime TIO warming is not strong enough to stimulate the Kelvin wave (Fig. 8a). Thus, the changes in springtime rainfall and convection over the TWNP do not suffer from the suppressing effect of the TIO warming (Fig. 8a, b).

To further verify the different strengths of TIO warming effect between spring and the other seasons on TWNP deep convection, we conduct several numerical experiments using the CAM5 model. Specifically, we add the observed TIO SST warming anomalies of the various seasons correspondingly in experiments TIO_MAM, TIO_ JJA, TIO_SON, and TIO_DJF (see Sect. 2.2 and Table 1). The changes in precipitation, convection, and $850-\mathrm{hPa}$ wind in response to the corresponding seasonal TIO warming are shown in Fig. 9. In response to the springtime TIO warming, very few changes in precipitation and OLR over the TIO are produced in the TIO_MAM run (Fig. 9a, b). On the other hand, significant anonymous westerly winds associated with the Rossby wave emerge over the western Indian Ocean (Fig. 9a), but no anonymous easterly winds associated with the Kelvin wave can be found in the eastern Indian Ocean and the western Pacific. Besides, there are only small changes in precipitation and OLR over the TWNP (Fig. 9a, b), agreeing with the observational analysis (Fig. 8a, b).

In the TIO_JJA, TIO_SON, and TIO_DJF runs, the magnitudes of increased precipitation over the western-central Indian Ocean are conspicuously larger than those in the TIO_MAM run, likely due to the stronger (observed) SST warming added into these simulations (Fig. 9c, e, g). Corresponding to the increased rainfall, there are substantial OLR reductions over the TIO, indicating significant strengthening 
Fig. 9 Differences in a MAM, c JJA, e SON, and $\mathbf{g}$ DJF precipitation (shading; $\mathrm{mm} \mathrm{day}^{-1}$ ) and 850-hPa wind (vector; $\mathrm{m} \mathrm{s}^{-1}$ ) between corresponding seasonal tropical Indian ocean warming experiments and control run (CTRL). $\mathbf{b}, \mathbf{d}, \mathbf{f}$, and $\mathbf{h}$ are the same as $\mathbf{a}, \mathbf{c}, \mathbf{e}$, and $\mathbf{g}$, but for OLR (shading; $\mathrm{W} \mathrm{m}^{-2}$ ). Dashed box indicates the TWNP region. Stippling indicates the significant values above the $99 \%$ confidence level

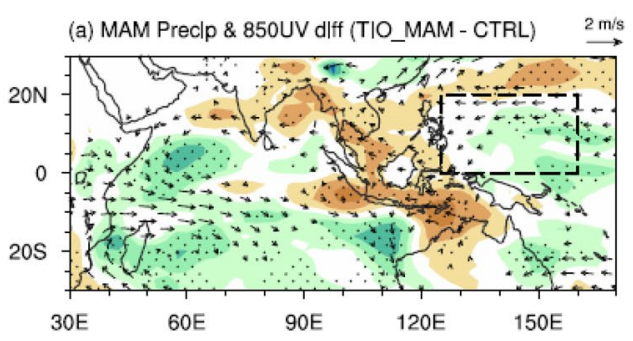

(b) MAM OLR dIff (TIO_MAM - CTRL)
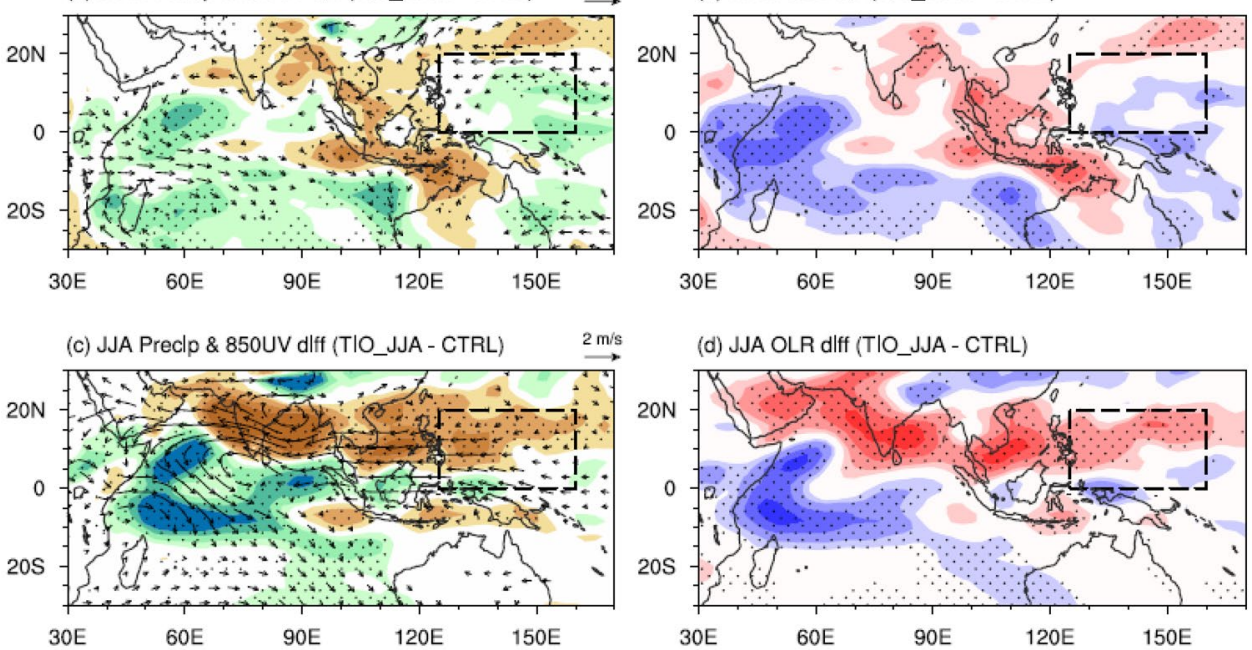

(d) JJA OLR dlff (TIO_JJA - CTRL)
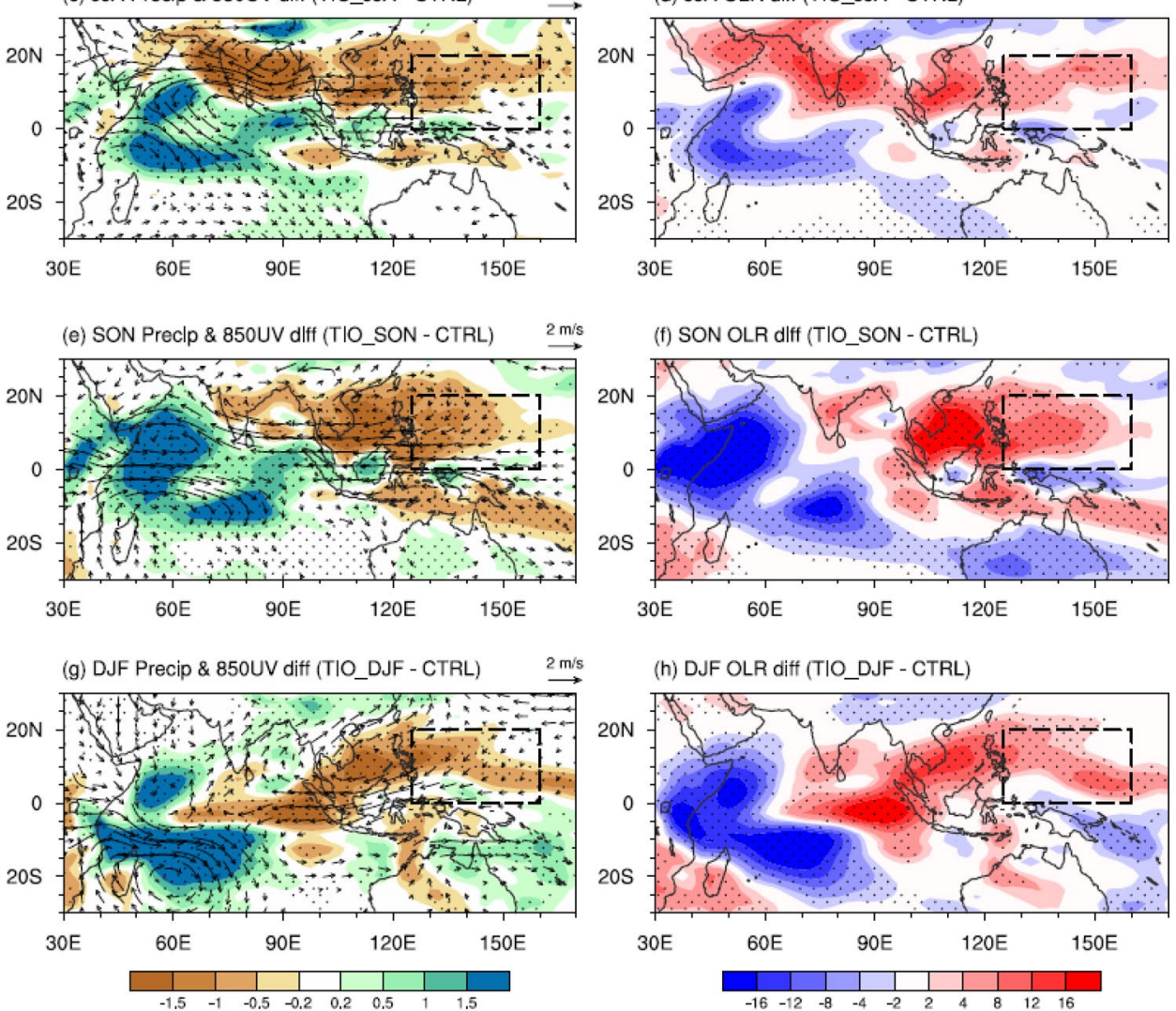

(h) DJF OLR diff (TIO_DJF - CTRL)

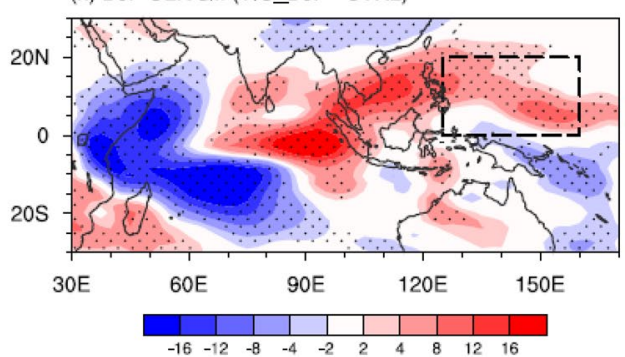

of deep convection (Fig. 9d, f, h). Although the magnitude and spatial patterns of the TIO warming induced changes in rainfall and OLR over TIO are somewhat different from the observations, model simulations indeed capture the observed seasonality of the changes in rainfall and OLR related to TIO warming. That is, more strongly enhanced deep convection and precipitation occur in the western TIO in summer, autumn, and winter. The notable Kelvin wave easterly wind anomalies over the eastern equatorial Indian Ocean to the western Pacific are thus produced (Fig. 9c, e, g), resulting in the anticyclonic shear in the off-equatorial regions of the SCS and the TNWP. Consequently, precipitation (Fig. 9c, e, g) and deep convection (Fig. 9d, f, h) are significantly suppressed over the SCS and the TWNP via above-mentioned Kelvin wave induced Ekman divergence mechanism in model simulations.
The results of model simulations further verify the negligible impact of TIO warming in boreal spring and the great suppressing effect in the other seasons. This seasonal difference in the influence of TIO warming on TWNP convection is mainly caused by the seasonality of the recent TIO warming. In all the seasons except spring, although the increase in local SST can strengthen TWNP deep convection (Fig. 6b-d), the concurrent TIO warming exerts a great negative impact on TWNP deep convection and thus cancel the SST warming induced increment. As a result, only small changes in the deep convection for these seasons are found over the TWNP (Fig. 3b, e, h). Consequently, diabatic heating increases most obviously in the boreal spring because of the largest increase in deep convection. 

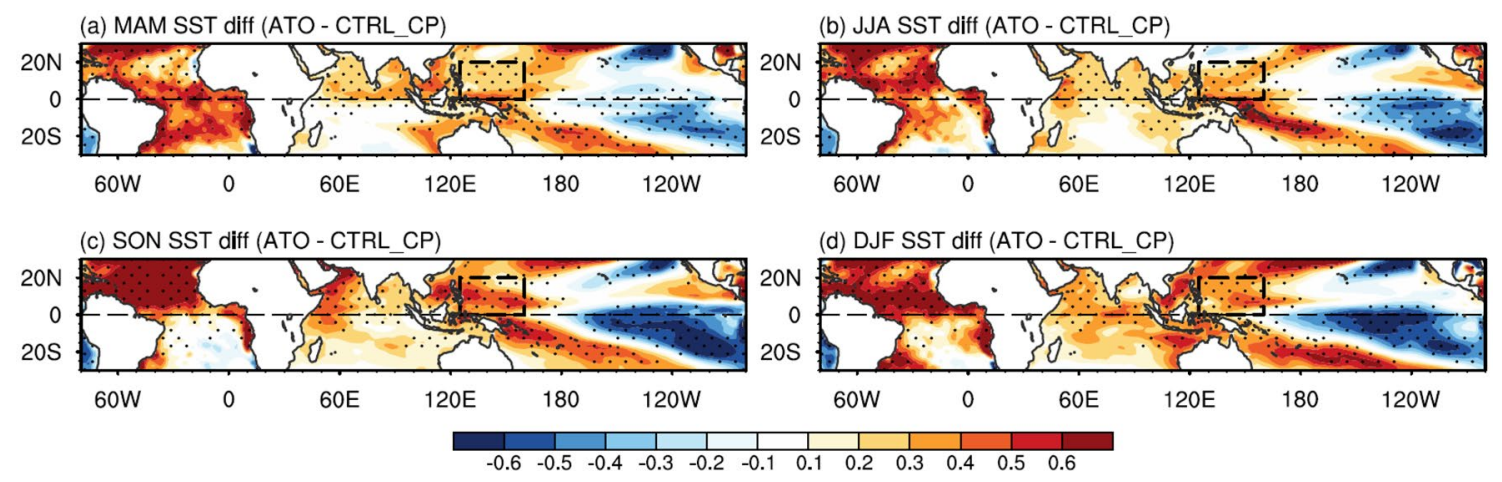

Fig. 10 Differences in a MAM, b JJA, c SON, and d DJF SST (shading; K) between the coupled simulation (ATO) forced by the observed tropical-Atlantic-only SST changes and coupled control run

\section{Summary and discussion}

We have examined the long-term changes in diabatic heating over the TWNP during 1979-2015 and found that diabatic heating has increased significantly in the boreal spring, caused by enhanced deep convection. However, in the other seasons no significant trends can be found due to the insignificant changes in deep convection. We explore the cause for this seasonality of the changes in diabatic heating by analyzing multiple observational and reanalysis datasets, and by performing several numerical experiments.

Two major factors lead to the noticeable seasonal dependence of the changes in diabatic heating during the recent decades. One factor is that the convection over the TWNP is more sensitive to SST in boreal spring than in the other seasons, because the springtime climatological SST is around the $28{ }^{\circ} \mathrm{C}$ threshold for convection development. As a result, the increased local SST can intensify deep convection more strongly in boreal spring, even though the magnitude of SST increase is close to that in the other seasons. The other factor is that the suppressing effect of the TIO warming on TWNP convection is negligible in boreal spring but quite strong in the other seasons. In all the seasons except spring, TIO warming induces abundant convective heating anomalies over the TIO, causing Kelvin wave easterly wind anomalies and resultant anticyclonic wind shear in the lower troposphere of the TWNP. Then, an anomalous boundarylayer divergence is induced by anomalous anticyclonic shear through Ekman pumping, which suppresses convection and precipitation over the TWNP. However, the suppressing effect is relatively insignificant in spring because the TIO warming in spring is much weaker than that in the other seasons. The weak springtime TIO warming cannot induce enough heating anomalies to excite a Kelvin wave, resulting in only a negligible impact on the TWNP convection. The differences in the TIO warming suppressing effect between spring and the other seasons are confirmed by sensitive
(CTRL_CP). Dashed box indicates the TWNP region. Stippling indicates the significant values above the $99 \%$ confidence level

experiments with the CAM5 model. In summary, the TIO warming in all the seasons except spring impedes the convection over the TWNP. The enhanced convection associated with local SST warming over the TWNP is thus offset by the influence of the TIO warming. The combined effect of the above-mentioned two factors causes deep convection to intensify in boreal spring, but causes insignificant changes in the other seasons. As a result, diabatic heating only increases significantly in the boreal spring.

In this study, we find that local SST warming dominantly contributes to the springtime enhanced deep convection and resultant increased diabatic heating over the TWNP during the recent decades. The SST warming over the TWNP co-occurs with the warming over the TIO in all four seasons. However, there is an apparent seasonality in the TIO warming, that is, the warming is weaker in boreal spring than in the other seasons. This seasonality is a factor that causes diabatic heating to increase over the TWNP most obviously in the boreal spring. The causes of these changes in SST over the recent decades need to be further discussed by future studies. Using a fully coupled climate model, $\mathrm{Li}$ et al. (2016a) argued that the tropical Atlantic (TA) warming could induce basin-scale SST warming over the TIO and the western Pacific through the atmospheric bridge. The TA warming induced SST anomalies contribute about 55-75\% of the tropical SST changes during the recent decades. Considering the great impact of recent TA warming on tropical SST, we speculate that the TA warming may also play an important role in the seasonality of TIO warming. To test this hypothesis, we conduct a fully coupled simulation, referred to as Exp ATO (see the Appendix). Forced by the observed TA warming, the Exp ATO captures the general features of the observed tropical-wide SST changes, that is, a significant SST warming in the Indo-western Pacific and a cooling in the eastern Pacific (Fig. 10). Furthermore, the seasonality of TIO warming is generally reproduced, characterized by a weaker warming in spring than in the 
other seasons, although the magnitude and spatial distributions of TIO warming are different from the observations (Fig. 10). The mechanisms for the impact of TA warming on the seasonality of TIO warming need to be discussed in future studies. Experiment Exp ATO also captures the observed seasonality of the changes in deep convection over the TWNP. A larger intensification of deep convection can be found in the boreal spring (Fig. 11), although local SST warming is relatively small than in other seasons (Fig. 10). This modeling result suggests that the seasonality of TWNP heating change during the recent decades can ultimately be traced back to the TA warming.

In this study, we find that the springtime deep convection over the TWNP has significantly intensified during the recent decades. This trend is inconsistent with the results shown in some previous studies (Held and Soden 2006; Zhang and Song 2006; Power and Smith 2007; Tokinaga et al. 2012), which stated a weakening annual-mean Walker circulation and a resultant suppression of deep convection over the western Pacific in a global warming context. However, several studies have showed that the annual-mean Walker circulation has indeed intensified in the recent decades (Sohn et al. 2013; England et al. 2014; McGregor et al. 2014; Ma and Zhou 2016). From the annual mean perspective, the long-term change in the Walker circulation is an open question. However, notably intensified deep convection over the TWNP is found in this study, at least in the spring season. Besides, Li et al. (2020) found a robust intensification of deep convection over the western Pacific in a long period (1901-2010). Moreover, this signal also exhibits a notable seasonal dependence: Rainfall and cloud cover display consistent and significant increasing trends only in the boreal spring. Therefore, even on a longer time scale, the changes in deep convection over the western Pacific still show a robust seasonality. Our results indicate that only focusing on the annual-mean variables may overlook the seasonal dependence of climate change signals and that more effort should be devoted to the study of such seasonality.

\section{Appendix}

\section{Linear congruency}

To investigate the changes in precipitation, wind, and convection as a response to the TIO warming, the linear congruency trends of these variables with the TIO warming are estimated using the technique outlined in Thompson et al. (2000). Under this approach, the trend of time series A that is linearly congruent with the trend of time series B is estimated as follows:

Trend $A_{\text {cong }}=R \times$ TrendB

where TrendA $A_{\text {cong }}$ is the fraction of linear trend in time series $\mathrm{A}$ that is linearly congruent with time series $\mathrm{B}, R$ is the regression coefficient describing the relationship between detrended time series $\mathrm{A}$ and B, and TrendB is the linear trend in time series B. In this study, time series A is the seasonal-mean precipitation, wind, and convection fields and time series B is the corresponding seasonal-mean TIO SST index obtained by averaging SST over the TIO $\left(40^{\circ}-110^{\circ} \mathrm{E} / 20^{\circ} \mathrm{S}-20^{\circ} \mathrm{N}\right)$.
Fig. 11 Differences in a MAM, b JJA, c SON, and d DJF OLR (shading; $\mathrm{W} \mathrm{m}^{-2}$ ) between the coupled simulation (ATO) forced by the observed tropical Atlantic SST warming anomalies and coupled control run (CTRL_CP). Dashed box indicates the TWNP region. Stippling indicates the significant values above the $99 \%$ confidence level (a) MAM OLR diff (ATO - CTRL_CP)

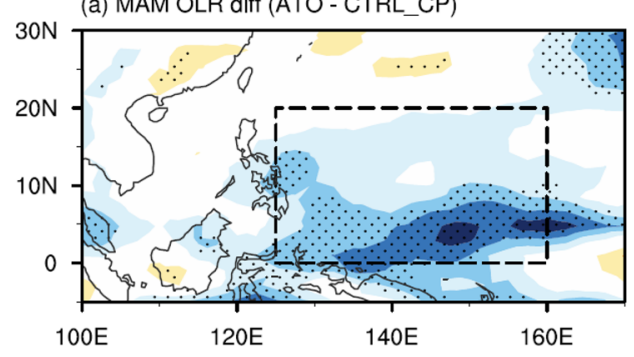

(c) SON OLR diff (ATO - CTRL_CP)

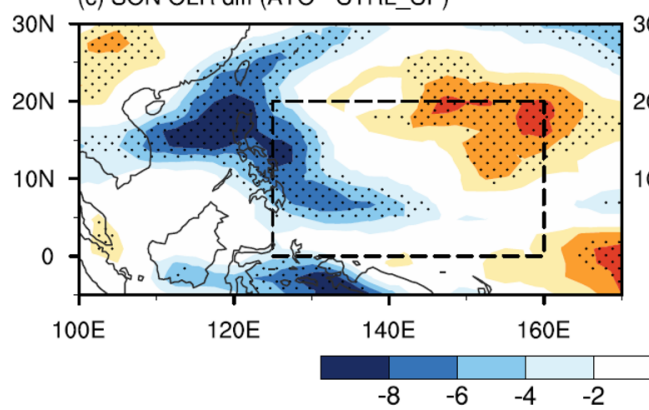

(b) JJA OLR diff (ATO - CTRL_CP)

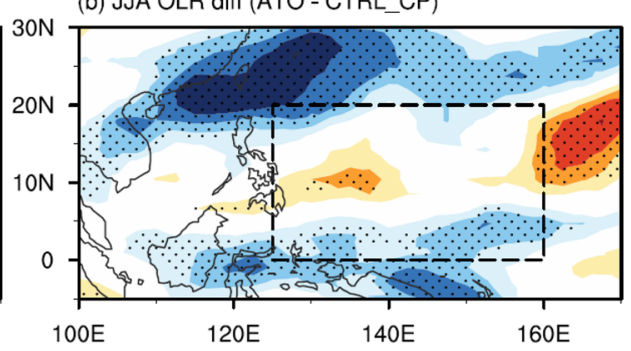

(d) DJF OLR diff (ATO - CTRL_CP)

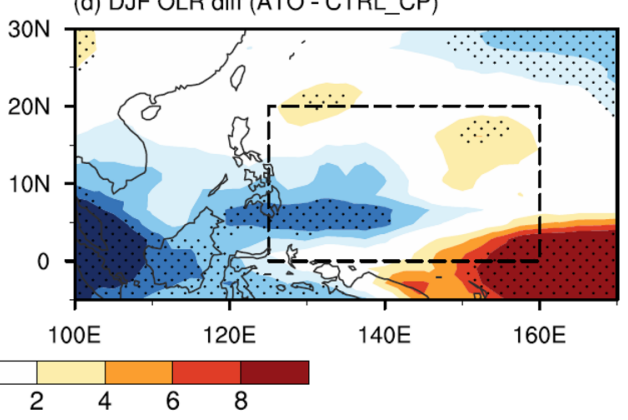


Table 2 Coupled CGCM experimental design

\begin{tabular}{ll}
\hline Exp & Description \\
\hline CTRL_CP & $\begin{array}{c}\text { CGCM run, the upper-5-m ocean temperature } \\
\text { in the tropical Atlantic Ocean }\left(80^{\circ} \mathrm{W}-20^{\circ} \mathrm{E},\right. \\
\\
\left.30^{\circ} \mathrm{S}-30^{\circ} \mathrm{N}\right) \text { is replaced with the model clima- } \\
\text { tology. Atmospheric and oceanic components } \\
\text { are freely coupled in the other ocean areas } \\
\text { Same as CTRL_CPL, but the upper-5-m ocean } \\
\text { temperature in the tropical Atlantic Ocean } \\
\text { is replaced with the model climatology plus } \\
\text { observed SST warming }\end{array}$ \\
\hline
\end{tabular}

\section{Coupled CESM experimental design}

To test whether the observed tropical Atlantic warming can induce the seasonality of TIO warming, we conduct a set of fully-coupled experiments using CESM 1.1.2. "B_2000 component set" is applied with a $1.9^{\circ} \times 2.5^{\circ}$ resolution in the atmospheric component and $\sim 1^{\circ}$ resolution in the ocean component in the coupled experiments. The solar forcing, greenhouse gases, ozone concentration, and aerosols are all fixed at the levels of year 2000. The total integration length of the control run (referred to as CTRL_CP) is 290 years. This simulation is first integrated for 250 years with freely coupled atmospheric and oceanic components. Then, we replace the first-layer (5-m depth) ocean temperature in the tropical Atlantic Ocean $\left(30^{\circ} \mathrm{S}-30^{\circ} \mathrm{N}\right.$, with a $5^{\circ}$ outer buffering zone) with the climatological annual cycle. As a result, we prescribe an annual cycle of the SST in the tropical Atlantic, but allow ocean-atmosphere coupling elsewhere. We run the model for 40 years starting from the 251 years and analyze the results of the last 35 years. A coupled perturbed run referred to as Exp ATO, which is similar to the control run, is restarted from year 251 of CTRL_CP and also integrated for 40 years. In Exp ATO, the tropical Atlantic SSTs are replaced with the model climatology plus observed SST warming anomalies (SST trend for 1979-2015 derived from the HadISST). The results from the last 35 years of Exp AT are analyzed. The difference between Exp ATO and CTRL_CP is then considered to be the CESM response to the observed tropical Atlantic warming. These coupled experiments are summarized in Table 2.

Acknowledgements The authors thank the three anonymous reviewers who provided constructive comments on the earlier version of the manuscript. This study was supported by the National Natural Science Foundation of China (Grants 41690123, 41690120 and 42088101), the Guangdong Major Project of Basic and Applied Basic Research (Grant 2020B0301030004), the Guangdong Province Key Laboratory for Climate Change and Natural Disaster Studies (Grant 2020B1212060025), and the Jiangsu Collaborative Innovation Center for Climate Change. The ERA-Interim reanalysis dataset was downloaded from https:// www.ecmwf.int/en/forecasts/datasets/reanalysis-datasets/era-interim. The GPCP precipitation, CMAP precipitation, NOAA interpolated OLR, NOAA ERSST4, and COBE SST datasets were obtained from the NOAA/OAR/ESRL PSD at https://www.esrl.noaa.gov/psd/, while the HadISST dataset was downloaded from the UK Met Office at https ://www.metoffice.gov.uk.

Open Access This article is licensed under a Creative Commons Attribution 4.0 International License, which permits use, sharing, adaptation, distribution and reproduction in any medium or format, as long as you give appropriate credit to the original author(s) and the source, provide a link to the Creative Commons licence, and indicate if changes were made. The images or other third party material in this article are included in the article's Creative Commons licence, unless indicated otherwise in a credit line to the material. If material is not included in the article's Creative Commons licence and your intended use is not permitted by statutory regulation or exceeds the permitted use, you will need to obtain permission directly from the copyright holder. To view a copy of this licence, visit http://creativecommons.org/licenses/by/4.0/.

\section{References}

Adler RF, Huffman GJ, Chang A et al (2003) The version 2 global precipitation climatology project (GPCP) monthly precipitation analysis (1979-present). J Hydrometeorol 2:2

Basist AN, Chelliah M (1997) Comparison of tropospheric temperatures derived from the NCEP/NCAR reanalysis, NCEP operational analysis, and the microwave sounding unit. Bull Am Meteorol Soc 78:1431-1447

Bengtsson L, Hagemann S, Hodges KI (2004) Can climate trends be calculated from reanalysis data? J Geophys Res Atmos 109:1-8. https://doi.org/10.1029/2004JD004536

Bhat GS, Srinivasan J, Gadgil S (1996) Tropical deep convection, convective available potential energy and sea surface temperature. J Meteorol Soc Japan 74:155-166. https://doi.org/10.2151/ jmsj1965.74.2_155

Cravatte S, Delcroix T, Zhang DX et al (2009) Observed freshening and warming of the western Pacific warm pool. Clim Dyn 33:565-589

Dee DP, Uppala SM, Simmons AJ et al (2011) The ERA-Interim reanalysis: configuration and performance of the data assimilation system. Q J R Meteorol Soc 137:553-597

England MH, Mcgregor S, Spence P et al (2014) Recent intensification of wind-driven circulation in the Pacific and the ongoing warming hiatus. Nat Clim Chang 4:222-227. https://doi.org/10.1038/ nclimate 2106

Firestone JK, Albrecht BA (1986) The structure of the atmospheric boundary layer in the coastal equatorial Pacific during January and February of FGGE. Mon Weather Rev 114:2219-2231

Folland CK, Parker DE (1995) Correction of instrumental biases in historical sea surface temperature data. Q J R Meteorol Soc 121:319-367

Gadgil S, Joseph PV, Joshi NV (1984) Ocean-atmosphere coupling over monsoon regions. Nature 312:141-143. https://doi.org/10. 1038/312141a0

Graham NE, Barnett TP (1987) Sea surface temperature, surface wind divergence, and convection over tropical oceans. Science 238:657-659

He B, Yang S, Li ZN (2016) Role of atmospheric heating over the South China Sea and western Pacific regions in modulating Asian summer climate under the global warming background. Clim Dyn 46:2897-2908. https://doi.org/10.1007/s00382-015-2739-2

Held IM, Soden BJ (2006) Robust responses of the hydrological cycle to global warming. J Clim 19:5686-5699. https://doi.org/10.1175/ JCLI3990.1 
Huang BY, Banzon VF, Freeman E et al (2015) Extended reconstructed sea surface temperature version 4 (ERSST.v4). Part I: upgrades and intercomparisons. J Clim 28:911-930. https://doi.org/10. 1175/JCLI-D-14-00006.1

Huang RH, Sun FY (1992) Impacts of the tropical western Pacific on the East Asian summer monsoon. J Meteorol Soc Japan 70:243-256

Hurrell JW, Holland MM, Gent PR et al (2013) The community earth system model: a framework for collaborative research. Bull Am Meteorol Soc 94:1339-1360

Johnson NC, Xie S-P (2010) Changes in the sea surface temperature threshold for tropical convection. Nat Geosci 3:842-845. https:// doi.org/10.1038/ngeo1008

Kim BH, Ha KJ (2015) Observed changes of global and western Pacific precipitation associated with global warming SST mode and mega-ENSO SST mode. Clim Dyn 45:3067-3075. https://doi. org/10.1007/s00382-015-2524-2

Kinter JL, Fennessy MJ, Krishnamurthy V, Marx L (2004) An evaluation of the apparent interdecadal shift in the tropical divergent circulation in the NCEP-NCAR reanalysis. J Clim 17:349-361

Lau KM, Wu HT, Bony S (1997) The role of large-scale atmospheric circulation in the relationship between tropical convection and sea surface temperature. J Clim 10:381-392

Li SL, Lu J, Huang G, Hu KM (2008) Tropical Indian Ocean basin warming and East Asian summer monsoon: a multiple AGCM study. J Clim 21:6080-6088

Li T, Wang B, Wu B et al (2017) Theories on formation of an anomalous anticyclone in western North Pacific during El Niño: a review. J Meteorol Res 31:987-1006. https://doi.org/10.1007/ s13351-017-7147-6

Li XC, Xie S-P, Gille ST, Yoo C (2016) Atlantic-induced pan-tropical climate change over the past three decades. Nat Clim Chang 6:275-279. https://doi.org/10.1175/2008JCLI2433.1

Li ZN, Yang S, He B, Hu CD (2016) Intensified springtime deep convection over the South China Sea and the Philippine Sea dries Southern China. Sci Rep 6:1-9. https://doi.org/10.1038/srep30470

Li ZN, Yang S, Tam CY, Hu CD (2020) Strengthening western equatorial Pacific and Maritime Continent atmospheric convection and its modulation on the trade wind during spring of 1901-2010. Int J Climatol. https://doi.org/10.1002/joc.6856

Liebmann S (1996) Description of a complete (interpolated) outgoing longwave radiation dataset. Bull Am Meteorol Soc 77:1275-1277

Lindzen RS, Nigam S (1987) On the role of sea surface temperature gradients in forcing low-level winds and convergence in the tropics. J Atmos Sci 44:2418-2436

Ling J, Zhang C (2013) Diabatic heating profiles in recent global reanalyses. J Clim 26:3307-3325. https://doi.org/10.1175/ JCLI-D-12-00384.1

Luo J-J, Sasaki W, Masumoto Y (2012) Indian Ocean warming modulates Pacific climate change. Proc Natl Acad Sci 109:18701-18706

Ma SM, Zhou TJ (2016) Robust strengthening and westward shift of the tropical Pacific Walker circulation during 1979-2012: a comparison of 7 sets of reanalysis data and 26 CMIP5 models. J Clim 29:3097-3118. https://doi.org/10.1175/JCLI-D-15-0398.1

McGregor S, Timmermann A, Stuecker MF et al (2014) Recent Walker circulation strengthening and Pacific cooling amplified by Atlantic warming. Nat Clim Chang 4:888-892. https://doi.org/10.1038/ nclimate 2330

Nitta T (1987) Convective activities in the tropical western Pacific and their impact on the northern hemisphere summer circulation. J Meteorol Soc Japan 65:373-390

Park JH, An S, Il (2014) The impact of tropical western Pacific convection on the North Pacific atmospheric circulation during the boreal winter. Clim Dyn 43:2227-2238

Power SB, Smith IN (2007) Weakening of the Walker circulation and apparent dominance of El Niño both reach record levels, but has
ENSO really changed? Geophys Res Lett 34:2-5. https://doi.org/ 10.1029/2007GL030854

Rayner NA, Parker DE, Horton EB et al (2003) Global analyses of sea surface temperature, sea ice, and night marine air temperature since the late nineteenth century. J Geophys Res Atmos 108:4407. https://doi.org/10.1029/2002jd002670

Rodwell MJ, Hoskins BJ (2001) Subtropical anticyclones and summer monsoons. J Clim 14:3192-3211

Roxy M (2014) Sensitivity of precipitation to sea surface temperature over the tropical summer monsoon region and its quantification. Clim Dyn 43:1159-1169

Sabin TP, Babu CA, Joseph PV (2013) SST-convection relation over tropical oceans. Int J Climatol 33:1424-1435. https://doi.org/10. 1002/joc. 3522

Saha S, Moorthi S, Pan HL et al (2010) The NCEP climate forecast system reanalysis. Bull Am Meteorol Soc 91:1015-1057. https:// doi.org/10.1175/2010BAMS3001.1

Seager R, Naik N, Vecchi GA (2010) Thermodynamic and dynamic mechanisms for large-scale changes in the hydrological cycle in response to global warming. J Clim 23(17):4651-4668

Simmons AJ (1982) The forcing of stationary wave motion by tropical diabatic heating. Q J R Meteorol Soc 108:503-534

Sohn BJ, Yeh SW, Schmetz J, Song HJ (2013) Observational evidences of Walker circulation change over the last 30 years contrasting with GCM results. Clim Dyn 40:1721-1732. https://doi.org/10. 1007/s00382-012-1484-z

Thompson DWJ, Wallace JM (2000) Annular modes in the extratropical circulation. Part II: trends. J Clim 13:1018-1036

Tokinaga H, Xie S-P, Timmermann A et al (2012) Regional patterns of tropical Indo-Pacific climate change: evidence of the Walker circulation weakening. J Clim 25:1689-1710. https://doi.org/10. 1175/JCLI-D-11-00263.1

Ueda H, Kamae Y, Hayasaki M et al (2015) Combined effects of recent Pacific cooling and Indian Ocean warming on the Asian monsoon. Nat Commun 6:1-8. https://doi.org/10.1038/ncomms9854

Waliser DE, Graham NE (1993) Convective cloud systems and warmpool sea surface temperatures: coupled interactions and self-regulation. J Geophys Res Atmos 98:12881-12893. https://doi.org/ 10.1029/93jd00872

Wang CZ (2000) On the atmospheric responses to tropical pacific heating during the mature phase of El Niño. J Atmos Sci 57:3767-3781

Webster PJ (1972) Response of the tropical atmosphere to local, steady forcing. Mon Weather Rev 100:518-541

Webster PJ, Lukas R (1992) TOGA COARE: the coupled ocean-atmosphere response experiment. Bull Am Meteorol Soc 73:1377-1416

Wu B, Zhou TJ, Li T (2009) Seasonally evolving dominant interannual variability modes of East Asian climate. J Clim 22:2992-3005

Wu R (2019) Summer precipitation-SST relationship on different time scales in the northern tropical Indian Ocean and western Pacific. Clim Dyn 52:5911-5926

Xie RH, Mu M, Fang XH (2020) New indices for better understanding ENSO by incorporating convection sensitivity to sea surface temperature. J Clim 33:7045-7061. https://doi.org/10.1175/ JCLI-D-19-0239.1

Xie S-P, Arkin PA (1997) Global precipitation: a 17-year monthly analysis based on gauge observations, satellite estimates, and numerical model outputs. Bull Am Meteorol Soc 78:2539-2558

Xie S-P, Hu KM, Hafner J et al (2009) Indian Ocean capacitor effect on Indo-Western pacific climate during the summer following El Niño. J Clim 22:730-747. https://doi.org/10.1175/2008JCLI25 44.1

Xie S-P, Kosaka Y, Du Y et al (2016) Indo-western Pacific ocean capacitor and coherent climate anomalies in post-ENSO summer: A review. Adv Atmos Sci 33:411-432. https://doi.org/10.1007/ s00376-015-5192-6 
Yanai M, Esbensen S, Chu J-H (1973) Determination of bulk properties of tropical cloud clusters from large-scale heat and moisture budgets. J Atmos Sci 30:611-627

Yang S, Webster PJ (1990) The effect of summer tropical heating on the location and intensity of the extratropical westerly jet streams. J Geophys Res Atmos. https://doi.org/10.1029/jd095id11p18705

Zhang C (1993) Large-scale variability of atmospheric deep convection in relation to sea surface temperature in the tropics. J Clim 6:1898-1913
Zhang MH, Song H (2006) Evidence of deceleration of atmospheric vertical overturning circulation over the tropical Pacific. Geophys Res Lett 33:1-5

Publisher's Note Springer Nature remains neutral with regard to jurisdictional claims in published maps and institutional affiliations. 